\title{
Self-Handicapping, Excuse Making, and Counterfactual Thinking: Consequences for Self-Esteem and Future Motivation
}

\author{
Sean M. McCrea \\ University of Konstanz
}

\begin{abstract}
Researchers interested in counterfactual thinking have often found that upward counterfactual thoughts lead to increased motivation to improve in the future, although at the cost of increased negative affect. The present studies suggest that because upward counterfactual thoughts indicate reasons for a poor performance, they can also serve as excuses. In this case, upward counterfactual thoughts should result in more positive self-esteem and reduced future motivation. Five studies demonstrated these effects in the context of self-handicapping. First, upward counterfactual thinking was increased in the presence of a self-handicap. Second, upward counterfactual thoughts indicating the presence of a self-handicap protected self-esteem following failure. Finally, upward counterfactual thoughts that protect self-esteem reduced preparation for a subsequent performance as well as performance itself. These findings suggest that the consequences of upward counterfactuals for affect and motivation are moderated by the goals of the individual as well as the content of the thoughts.
\end{abstract}

Keywords: counterfactual thinking, self-handicapping, self-protection, motivation

Counterfactual thinking involves considering how a past event could have been better or worse. Those thoughts that identify how an outcome could have been worse (e.g., "At least I passed the test, I could have failed") are referred to as downward thoughts, whereas those that identify how an outcome could have been better (e.g., "If I had studied more, I could have gotten an A") are referred to as upward thoughts (Markman, Gavanski, Sherman, \& McMullen, 1993, 1995; Roese, 1994).

An extensive body of research has documented the consequences of these thoughts for affect and subsequent behavior (for reviews, see Epstude \& Roese, 2008; Markman \& McMullen, 2003; Roese \& Olson, 1995a; Sanna, Carter, \& Small, 2006). Previous research on counterfactual thinking has found that individuals often compare counterfactual alternatives to reality, leading to an affective contrast effect (Markman \& McMullen, 2003; McMullen, 1997). Thus, upward counterfactual thoughts can lead to more negative affect, whereas downward counterfactual thoughts can lead to maintained or more positive affect (Boninger, Gleicher, \& Strathman, 1994; Markman et al., 1993, 1995; Roese, 1994). These findings led to the conclusion that downward counterfactuals often serve an affective (i.e., mood maintenance) function (Markman et al., 1993; Roese, 1994).

In terms of the behavioral consequences of counterfactual thinking, past researchers have often found that upward counterfactuals

This research was completed with the support of a dissertation fellowship from Indiana University and research grants from the University of Konstanz (AFF 13/05) and the German Research Foundation (DFG MC 68/1-1). I wish to especially thank Ed Hirt, Jim Sherman, Russ Fazio, Nira Liberman, and Sarah Queller for their helpful suggestions in this research, and Stefanie Hehn and Ruprecht Lindhorst for serving as experimenters.

Correspondence concerning this article should be addressed to Sean M. McCrea, Department of Psychology, Fach D-39, University of Konstanz, 78457 Konstanz, Germany. E-mail: Sean.McCrea@uni-konstanz.de lead to greater intentions to prepare, greater task effort, and improved performance (Markman et al., 1993; Markman, McMullen, \& Elizaga, 2008; Myers \& McCrea, 2008; Roese, 1994), suggesting that upward counterfactual thoughts often serve a preparative function. Several possible processes underlying this effect have been suggested, although they may operate in tandem and are not mutually exclusive (Epstude \& Roese, 2008). Thinking "If I had studied more I would have gotten an A" might lead to increased studying because the individual is less satisfied with his or her performance and thus more motivated to improve (Markman \& McMullen, 2003; Markman et al., 2008; Myers \& McCrea, 2008), because the thought identifies a potentially useful behavior (Epstude \& Roese, 2008; Roese, 1994; Roese \& Olson, 1995b), or because the individual experiences increased self-efficacy (Tal-Or, Boninger, \& Gleicher, 2004). Supporting the proposed motivational benefits of counterfactual thinking, numerous studies have shown that performance benefits of counterfactual thinking only occur when accompanied by negative affect (Markman et al., 2008; McMullen \& Markman, 2000; Myers \& McCrea, 2008). Thus, counterfactual thinking appears to involve a tradeoff of protecting affect for improving future performance.

More recent research has suggested that these consequences of upward and downward counterfactual thinking can also be reversed. The Reflection Evaluation Model (Markman \& McMullen, 2003; Markman et al., 2008; McMullen, 1997) holds that focusing individuals on the counterfactual alternative (i.e., reflection) rather than on a comparison of this alternative with the obtained outcome (i.e., evaluation) leads to more positive affect as a result of making upward compared to downward counterfactuals and increased preparation and motivation as a result of making downward compared to upward counterfactuals. Thus, fantasizing that an outcome could have been better leads to more positive affect, which in turn undermines efforts to improve in the future (Markman \& McMullen, 2003; Markman et al., 2008). Outcomes that cannot be 
changed and outcome accountability also tend to evoke affective contrast effects of counterfactual thinking, whereas the possibility to change an outcome in the future and process accountability tend to evoke affective assimilation effects of counterfactual thinking (Boninger et al., 1994; Markman \& Tetlock, 2000a; McMullen \& Markman, 2002).

The present article suggests that another variable that can moderate the affective and motivational consequences of upward counterfactual thinking is the desire to excuse poor performances and protect self-esteem. Consider for a moment the thought, "If I had studied more, I could have gotten an A." In those cases in which the individual is motivated to achieve, such a thought would lead one to experience disappointment and self-directed anger because a better outcome could have been obtained. These emotions would in turn motivate efforts to improve subsequent academic performance. This type of effect has been documented extensively in counterfactual studies (e.g., Markman et al., 1993, 2008; Myers \& McCrea, 2008; Roese, 1994). However, in situations in which the individual is motivated by self-protection concerns, the same thought could be used to suggest that a poor grade was due to a lack of effort rather than a lack of ability or intelligence. As a result, one might expect this same type of thought to protect self-esteem following a failure (thus serving an affective function) but undermine motivation to improve.

There is of course a large literature demonstrating that the impact of performance feedback on self-esteem is moderated by attribution processes. Failures lead to lower self-esteem when attributed to internal stable causes, such as ability, than when attributed to external or unstable causes, such as low effort or task difficulty (Covington \& Omelich, 1979; McFarland \& Ross, 1982; Weiner, 1985). Research on counterfactual thinking has shown that there are also close links between these thoughts and causal judgments, particularly blame assignment, although they do not completely overlap with attribution processes (Branscombe, Wohl, Owen, Allison, \& N'Gbala, 2003; Creyer \& Guerhan, 1997; Mandel, 2003; Mandel \& Lehman, 1996; Wells \& Gavanski, 1989). For example, one could say a fire destroyed the house but that this outcome could have been prevented had the fire department responded more quickly. It is therefore likely that the ramifications of counterfactual thoughts for blame and responsibility should influence subsequent affect and self-esteem, independent of attribution processes. Counterfactual thoughts blaming low ability for a poor performance are likely to result in decreased self-esteem, relative to counterfactuals placing blame on more unstable factors (see also Covington \& Omelich, 1979; Weiner, 1985).

Indeed, research has demonstrated that counterfactuals mutating aspects of the self as opposed to more external factors have more negative consequences for emotion and well-being following a negative event. For example, counterfactuals that mutate aspects of the self following a failure lead to increased shame (Niedenthal, Tangney, \& Gavanski, 1994) and regret (Sevdalis \& Kokkinaki, 2006), and agreement with such thoughts predicts increased selfblame and worse psychological well-being following a traumatic event (Branscombe et al., 2003). Individuals also demonstrate a number of self- and group-protective biases in counterfactual thinking. For example, following a negative outcome, individuals are more likely to generate counterfactuals indicating that it was unforeseeable (Markman \& Tetlock, 2000b). They are also more likely to agree with upward counterfactuals when seeking to lower expectations for future performances (Sanna, Chang, \& Meier, 2001). Following a failure relevant for the self or an ingroup, individuals tend to mutate external factors more than they do internal factors; conversely, following a success, they tend to mutate internal factors more than they do external factors (Goerke, Möller, Schulz-Hardt, Napiersky, \& Frey, 2004; Roese \& Olson, 1993). This pattern of counterfactual mutation is not found or is reversed for the outcomes of others (McCrea, 2007; Roese \& Olson, 1993). Thus, there is increasing evidence that counterfactual thoughts are biased by self-protection concerns. However, to date there has not been direct evidence for the use of counterfactuals to blame poor outcomes on unstable factors (such as lack of effort) nor has research examined the consequences of such thoughts for self-esteem and motivation.

\section{Self-Handicapping}

The current studies sought to provide evidence for the ability of upward counterfactuals to excuse poor performances in the context of self-handicapping. Self-handicapping involves creating or claiming an obstacle prior to a performance (Berglas \& Jones, 1978; Jones \& Berglas, 1978). In the event of a failure, one can point to the self-handicap as the reason a better outcome was not obtained and thereby protect self-esteem and conceptions of ability (Feick \& Rhodewalt, 1997; McCrea \& Hirt, 2001; Rhodewalt, Morf, Hazlett, \& Fairfield, 1991). Past research has shown that individuals use a variety of strategies to self-handicap, including withdrawing effort (Hirt, Deppe, \& Gordon, 1991; Hirt, McCrea, \& Kimble, 2000), listening to distracting music (Shepperd \& Arkin, 1989b), or ingesting drugs or alcohol (Berglas \& Jones, 1978; Jones \& Berglas, 1978) prior to an important exam or performance. Self-handicapping is more likely to occur when individuals are feeling uncertain about an important performance. For example, receiving noncontingent success feedback (Berglas \& Jones, 1978) or experiencing uncertainty and concern as a result of public self-focus (Hirt et al., 2000) increases self-handicapping. Men are also more willing to engage in active, behavioral forms of self-handicapping, such as withdrawal of preparation effort, taking drugs or alcohol, or listening to distracting music, than are women (Hirt et al., 1991, 2000; McCrea, Hirt, \& Milner, 2008; Rhodewalt, 1990; Shepperd \& Arkin, 1989b). This difference appears to be due to the fact that women place more value on putting forth one's best effort than do men (McCrea, Hirt, Hendrix, Milner, \& Steele, in press; McCrea et al., 2008).

Research has also demonstrated that self-handicapping is effective in protecting self-esteem and conceptions of ability in the face of failure. Specifically, the presence of a handicap allows individuals to shift attributions for a poor performance from ability to the handicap (Feick \& Rhodewalt, 1997; McCrea \& Hirt, 2001; Rhodewalt et al., 1991). In addition, self-handicapping maintains self-evaluations of ability in a specific domain, as well as global self-esteem, despite failure (Feick \& Rhodewalt, 1997; McCrea \& Hirt, 2001).

\section{Counterfactual Thinking and Self-Handicapping}

Given the relationship between counterfactual thinking, blame assignment, and affect, as well as the reliance of the selfhandicapping strategy on manipulating subsequent attributions, it 
may prove interesting to examine the role of counterfactual thinking in self-handicapping. S. J. Sherman and McConnell (1995) noted that, by deliberately creating obstacles to success, the selfhandicapping strategy appears to increase the likelihood that upward counterfactuals will be generated. Self-handicaps are likely to be the focus of counterfactual explanations for a poor performance because they represent an "abnormal" condition (Kahneman \& Miller, 1986). However, at least with regard to self-esteem, the consequences of upward counterfactuals that identify a selfhandicap are likely to be positive rather than negative. That is, in the context of self-handicapping, thinking "If I had studied more, I would have gotten an A" should maintain self-esteem following a poor performance (S. J. Sherman \& McConnell, 1995). Thus, counterfactuals are particularly likely to excuse failure when the thought identifies a salient self-handicap. In attribution terms, counterfactuals that identify unstable factors as having prevented a better performance should serve to protect self-esteem following failure (see also Covington \& Omelich, 1979; Weiner, 1985).

In addition to examining the consequences of using excusing upward counterfactual thoughts for self-esteem, the present studies examine how future motivation is likely to be impacted. If increased motivation resulting from counterfactual thinking is dependent upon the experience of negative affect, then it may not occur for upward thoughts that identify an excuse for failure. That is, an excuse may allow the individual to be satisfied with his or her performance despite failure, thus eliminating the motivation to improve in the future. Interestingly, this would suggest that selfhandicapping on an initial performance is likely to decrease motivation to improve. As a result, preparatory effort and subsequent performance should suffer. This prediction, although untested to date, would potentially account for past findings that selfhandicapping behavior can undermine long-term academic performance (McCrea \& Hirt, 2001; Urdan, 2004; Zuckerman, Kieffer, \& Knee, 1998).

\section{Study 1 -Counterfactuals in the Classroom}

Study 1 sought to provide initial evidence for the use of upward counterfactuals as excuses in a situation in which individuals would be motivated by self-protection concerns. Specifically, participants generated counterfactual thoughts following a midterm examination in their psychology course in which a lack of study effort could have served as a self-handicap. Individuals reporting low preparatory effort for the course exam were expected to generate more upward counterfactual thoughts about their effort relative to those reporting high preparatory effort for the exam. Furthermore, controlling for reported effort, individuals were expected to experience higher self-esteem as a result of generating upward counterfactuals about a lack of effort. Given that past work has shown that upward counterfactuals involve a tradeoff of increased negative affect for increased preparative intentions and performance (Markman et al., 1993; Myers \& McCrea, 2008; Roese, 1994), individuals using upward counterfactuals to excuse a poor performance should experience less dissatisfaction and therefore be less motivated to improve in the future. Thus, individuals generating more upward counterfactuals about effort should report higher intentions to prepare in the future but only when these thoughts are accompanied by lower self-esteem. These effects of counterfactual thinking were expected to be limited to those specifically related to the handicap. Given that other counterfactuals are likely to mutate a mix of external and internal, stable and unstable factors, no predictions were made with regard to the effects of thoughts unrelated to the handicap for self-esteem or subsequent motivation.

Finally, attributions to effort were measured to assess whether effects of counterfactual thinking occurred independently of causal attribution. Based on previous research showing that counterfactual thinking and attribution are related but independent processes (Mandel, 2003; Mandel \& Lehman, 1996), it was predicted that effort attributions would show similar effects but would not account for the effects of counterfactuals concerning the handicap.

\section{Method}

\section{Participants}

Participants were 125 (35 men, 90 women) Indiana University students in two sections of a social psychology course who participated in return for extra credit in the course. There was no mention of self-handicapping or counterfactual thought in either class. Both sections used the same text, the same test format, and the same timing of the test.

\section{Materials and Procedure}

Study 1 involved three sessions, following the methods of McCrea and Hirt (2001). The first session occurred at the beginning of the semester. The second occurred approximately 1 week before a midterm exam in the course. The third occurred approximately 1 week after the exam, immediately after participants learned their score.

Session 1. Participants were told that the experimenters were interested in how students at large and small universities prepare for exams. They completed a detailed informed consent form and were assured their responses would be kept confidential, being identified only by a unique code. They were asked to complete a personality profile that included Rosenberg's (1965) self-esteem measure, answering on a 1 (strongly agree) to 7 (strongly disagree) scale.

Session 2. Participants were told that the researchers were interested in a number of factors, such as class size, that might influence how students prepare for tests. Participants were asked to complete several demographic measures, to provide their most recent GPA (high school or college) and college entrance exam scores (on a scale ranging from $1=<600$ SAT or $<18$ ACT to $10=1500-1600 S A T$ or $34-36 A C T$ ), and to complete several items concerning the characteristics of their class and the instructor to solidify the cover story.

Session 3. The final session occurred immediately after participants learned their score on the test. Participants indicated their score (percent correct) on the exam. They were then asked to list any thoughts they had about their test score. Thus, there were no explicit instructions concerning counterfactual thoughts. Participants then were asked whether their performance was due to their amount of effort, rated on a scale ranging from 1 (disagree very much) to 7 (agree very much), and completed a measure of mood and self-esteem. They indicated to what extent they felt each of 30 mood and self-esteem adjectives (adapted from McFarland \& 
Table 1

Future Study Intention Interitem Correlations (Study 1; $N=125$ )

\begin{tabular}{|c|c|c|c|c|c|c|c|c|}
\hline Item & Textbook & Flashcards & Asking instructor & Asking others & Office hours & Review session & Days & Overall \\
\hline Textbook & - & & & & & & & \\
\hline Flashcards & $.42^{* * * * *}$ & - & & & & & & \\
\hline Asking instructor & $.20^{*}$ & $.27^{* * *}$ & - & & & & & \\
\hline Asking others & $.29^{* * *}$ & $.39^{* * * * *}$ & $.49^{* * * *}$ & - & & & & \\
\hline Office hours & $.36^{* * * *}$ & $.35^{* * * *}$ & $.48^{* * * *}$ & $.42^{* * * *}$ & - & & & \\
\hline Review session & $.35^{* * * *}$ & $.38^{* * * *}$ & $.37^{* * * * *}$ & $.39^{* * * *}$ & $.46^{* * * *}$ & - & & \\
\hline Days & $.41^{* * * *}$ & $.33^{* * * *}$ & .13 & $.32^{* * * *}$ & $.38^{* * * *}$ & $.44^{* * * * *}$ & - & \\
\hline Overall & $.63^{* * * *}$ & $.47^{* * * *}$ & $.23^{* * *}$ & $.35^{* * * *}$ & $.50^{* * * *}$ & $.46^{* * * *}$ & $.40^{* * * *}$ & - \\
\hline$M$ & 4.90 & 3.14 & 2.08 & 2.40 & 1.54 & 3.24 & 5.25 & 5.98 \\
\hline$S D$ & 1.56 & 2.49 & 1.78 & 1.98 & 1.70 & 2.41 & 3.66 & 0.96 \\
\hline
\end{tabular}

${ }^{*} p<.05 .^{* * *} p<.01 .^{* * * *} p<.001$.

Ross, 1982) at that moment using a 1 (not at all) to 7 (very much) scale.

They next indicated how much effort they had put into studying for the exam (see also McCrea \& Hirt, 2001). Participants completed measures assessing how much they had read the textbook, attended office hours, went to review sessions, used flash cards, asked the instructor questions, and asked other students questions. They responded to these items using a 0 (not at all) to 6 (great deal) scale. They also indicated how hard they had studied overall on a 1 (not at all) to 7 (very much) scale and reported how many days before the exam they had studied. Finally, participants reported their intentions to study for the next exam in the class using the same items. At the end of the final session, the full purpose of the experiment, reason for the use of deception, and expected results were discussed with participants. The confidentiality of their responses was again stressed.

\section{Results}

\section{Overview}

Regression analyses were utilized due to the continuous nature of the data. All variables were centered around the mean and significant interactions were probed using simple-slope tests calculated at \pm 1 standard deviation from the mean (Aiken \& West, 1991). Predicted scores were plotted at \pm 1 standard deviation from the mean and $95 \%$ confidence intervals for the simple slopes were also calculated (Tabachnik \& Fidell, 2001). Reported study effort items were highly correlated, as were the future study intention items. They were therefore standardized and summed to form single indices (reported study effort $\alpha=.69$; future study intentions $\alpha=.83$ ). Means, standard deviations, and interitem correlations for the future study intention items are provided in Table 1. Based on correlational and reliability analyses, a postexam state self-esteem index (worthless, depressed, incompetent, stupid, inadequate, shame; $\alpha=.96$ ) and a positive mood index (joyful, delighted, happy, excited, glad, satisfied, confident; $\alpha=.97$ ) were created (see also McCrea \& Hirt, 2001). Higher scores on the self-esteem index reflected less (i.e., more negative) self-esteem. Initial analyses revealed no significant effects of gender, and so this variable is not discussed further. Univariate and bivariate statistics for the main variables are presented in Table 2.

\section{Counterfactual Thoughts}

Two coders identified any thoughts that indicated how the test score could have been better or worse. Only those thoughts mentioning a factor that could have affected the outcome of the psychology exam (and not things affecting other events or the person's emotional state) were included. Thus, thoughts expressing satisfaction or disappointment with the outcome were excluded. Those thoughts indicating how the test score could have been improved above the actual score were coded as upward, whereas those thoughts indicating how the test score could have been worse than the actual score were coded as downward. Due to the open-ended nature of the thought listing instructions, it was not crucial that the thought followed a strict if-then format but rather that the thought indicated that the outcome could have been different. For example, the thought, "The essay is what messed up my grade because I hadn't studied that subject thoroughly enough," was classified as an upward counterfactual even though the if-then phrasing was not explicitly given. In addition, the content of the counterfactual thoughts was classified as concerning either the amount (or lack) of study effort and preparatory behavior or other miscellaneous factors. Included in the miscellaneous category were thoughts about interest in and importance of the exam, the difficulty of the exam, understanding the material, stress or anxiety, attention and concentration, time allowed for the exam, etc. For example, the thought "I think I could have done better if I would have put a little more time studying [sic]" was classified as a study thought, whereas the thought "Some of the questions I missed, first I' $d$ circled the right answer and then I doubted myself so I changed them" was classified as miscellaneous. Interrater agreement for these judgments was $83 \%(\kappa=.53)$, and disagreements were resolved through discussion. Participants generated relatively few $(f=18)$ downward counterfactual thoughts, and so they were excluded from the analyses. ${ }^{1}$

\footnotetext{
${ }^{1}$ Including downward thoughts in the analyses either as a separate variable or by creating an index by subtracting the number of downward counterfactual thoughts from the number of upward counterfactual thoughts (see also Markman et al., 1993, 1995) did not alter the results. The number of downward thoughts predicted increased positive affect, but there were no other effects of these thoughts.
} 
Table 2

Zero-Order Correlations (Study $1 ; N=125$ )

\begin{tabular}{|c|c|c|c|c|c|c|c|}
\hline Measure & $\begin{array}{c}\text { Upward study } \\
\text { thoughts }\end{array}$ & $\begin{array}{c}\text { Upward } \\
\text { miscellaneous } \\
\text { thoughts }\end{array}$ & Performance & $\begin{array}{c}\text { Effort } \\
\text { attribution }\end{array}$ & $\begin{array}{c}\text { Post } \\
\text { self-esteem }\end{array}$ & $\begin{array}{l}\text { Positive } \\
\text { mood }\end{array}$ & $\begin{array}{c}\text { Future study } \\
\text { intentions }\end{array}$ \\
\hline Upward study thoughts & - & & & & & & \\
\hline Upward miscellaneous thoughts & -.10 & - & & & & & \\
\hline Performance & .02 & $-.19^{*}$ & - & & & & \\
\hline Effort attribution & .16 & $-.27^{* *}$ & $.32^{\text {***** }}$ & - & & & \\
\hline Post self-esteem & -.17 & .12 & $-.62^{* * * *}$ & $-.47^{* * * *}$ & - & & \\
\hline Positive mood & -.03 & $-.22^{*}$ & $.71^{\text {***** }}$ & $.40^{* * * *}$ & $-.70^{* * * *}$ & - & \\
\hline Future study intentions & $-.27^{* *}$ & .15 & $-.48^{* * * *}$ & $-.20^{*}$ & $.47^{* * * * *}$ & $-.35^{* * *}$ & - \\
\hline$M$ & 0.22 & 0.38 & 0.76 & 4.31 & 14.59 & 23.95 & 0.05 \\
\hline$S D$ & 0.44 & 0.63 & 0.14 & 1.85 & 9.86 & 13.08 & 5.42 \\
\hline
\end{tabular}

${ }^{*} p<.05 .^{* * *} p<.01 .{ }^{* * * *} p<.001$.

The number of upward study counterfactual thoughts $(f=28)$ and upward miscellaneous counterfactual thoughts $(f=47)$ were separately regressed on performance on the exam and on the reported study effort index. Those reporting lower study effort made more upward counterfactual thoughts than did those reporting higher study effort, $\beta=-.413, t(119)=4.94, p<.001, f^{2}=$ .17. There was no effect of performance $\left(t<1, n s, f^{2}=.00\right)$.

A marginal effect of performance was found on the number of miscellaneous upward counterfactuals, $\beta=-.171, t(119)=1.92$, $p<.06, f^{2}=.03$. Those performing poorly on the exam tended to make more upward counterfactual thoughts than did those performing well. There was no effect of reported study effort, $\beta=$ $.141, t(119)=1.57, p=.11, f^{2}=.02$.

\section{Effort Attribution}

Attributions of performance to effort were regressed on the following model: reported study intentions, performance on exam, number of upward study thoughts, number of upward miscellaneous thoughts, and the interaction of these counterfactual variables with performance on the exam. Significant predictors of effort attributions were performance, $\beta=.254, t(115)=3.11, p<$ $.01, f^{2}=.08$, and the number of miscellaneous counterfactual thoughts, $\beta=-.231, t(115)=2.73, p<.01, f^{2}=.06$. Participants made more attributions to effort when they performed well and when they had made fewer upward miscellaneous counterfactuals. In addition, the Performance $\times$ Number of Upward Study Counterfactuals interaction was significant, $\beta=-.305, t(115)=$ $3.79, p<.001, f^{2}=.11$ (see Figure 1 ). Upward study counterfactual thoughts were associated with increased attributions to effort for a poor performance (simple-slope $=2.07$ ), $t(121)=$ 4.16, $p<.001, f^{2}=.12,95 \% \mathrm{CI}: 1.09$ to 3.06 , but not for a successful performance (simple-slope $=-0.69), t(121)=1.41$, $p=.16, f^{2}=.02,95 \% \mathrm{CI}:-1.66$ to 0.28 .

\section{Postexam Mood and Self-Esteem}

The positive mood and negative self-esteem indices were regressed onto the following model: Rosenberg Self-Esteem scores $(\alpha=.90, M=53.47, S D=10.83)$, GPA $(M=3.26, S D=0.44)$, and standardized test scores $(M=6.03, S D=1.68)$ were included in an initial step. Performance on the exam, number of upward study thoughts, number of upward miscellaneous thoughts, and the interaction of these counterfactual variables with performance were included in a second step.

The analysis predicting positive mood revealed that those scoring better on the exam reported more positive mood, $\beta=.762$, $t(111)=9.49, p<.001, f^{2}=.45$. There were no other effects on this measure (all $t \mathrm{~s}<1.67, p \mathrm{~s}>.09, f^{2}<.09$ ).

The analysis predicting postexam negative self-esteem revealed an effect of Rosenberg Self-Esteem scores, $\beta=-.227, t(111)=$ $3.21, p<.01, f^{2}=.09$, confirming that this measure was actually tapping self-esteem. In addition, those scoring worse on the exam reported more postexam negative self-esteem, $\beta=-.728$, $t(111)=8.57, p<.001, f^{2}=.40$. Finally, those generating more upward counterfactual thoughts about studying reported less postexam negative self-esteem, $\beta=-.171, t(111)=2.48, p<.05$, $f^{2}=.05$. There were no other effects on this measure (all $t \mathrm{~s}<$ $\left.1.67, p s>.09, f^{2}<.03\right)$.

An additional analysis was conducted to examine whether the effects of upward study thoughts on postexam self-esteem could be explained by attributions to effort. Therefore, the effort attribution measure as well as the interaction of this variable with performance was added to the model in a final step. Effort attributions were indeed a significant predictor of postexam self-esteem, $\beta=$ $-.333, t(109)=4.45, p<.001, f^{2}=.15$. Individuals reported less negative postexam self-esteem when they attributed their perfor-

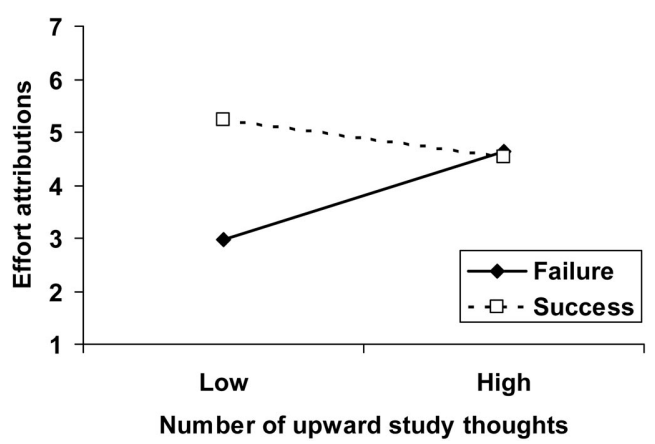

Figure 1. Effect of the Performance $\times$ Number of Upward Study Thoughts interaction on effort attributions (Study 1). 
mance to effort. More importantly, the upward study counterfactual effect remained significant, $\beta=-.140, t(109)=2.09, p<$ $.05, f^{2}=.04$. Thus, the effects of these thoughts were not explained by effort attributions.

\section{Future Study Intentions}

The future study intention index was regressed onto the following model: Reported study effort, Rosenberg Self-Esteem scores, GPA, standardized test scores, and performance on the exam were included in an initial step. Number of upward study thoughts, number of upward miscellaneous thoughts, negative postexam self-esteem, and the interactions of the counterfactual variables with negative postexam self-esteem were added in a second step. The analysis predicting future study intentions revealed effects of reported study effort, $\beta=.633, t(101)=9.94, p<.001, f^{2}=.49$, and performance, $\beta=-.230, t(101)=2.49, p<.05, f^{2}=.06$, indicating that those who reported higher study effort and scored worse on the exam reported higher intentions to study in the future. In addition, there was an effect of negative postexam self-esteem, $\beta=.251, t(101)=2.97, p<.01, f^{2}=.08$, such that those reporting more negative postexam self-esteem intended to study more. Finally, the interaction of number of upward study thoughts and negative self-esteem was significant, $\beta=.231, t(101)=3.66$, $p<.001, f^{2}=.12$ (see Figure 2). Simple-slopes tests were conducted controlling for reported study effort, Rosenberg SelfEsteem scores, performance on the exam, SAT scores, and GPA. These analyses revealed that, among those experiencing more negative postexam self-esteem, the effect of number of upward study thoughts was positive and significant (simple-slope $=4.73$ ), $t(103)=3.31, p<.01, f^{2}=.09,95 \%$ CI: 1.89 to 7.56 . Thus, these individuals demonstrated higher future study intentions after generating more upward study counterfactuals. Among those experiencing less negative self-esteem, the effect of number of upward study thoughts was negative and significant (simple-slope = $-2.24), t(103)=2.16, p<.05, f^{2}=.04,95 \%$ CI: -4.30 to -0.19 . Thus, these individuals showed the reverse effect, namely, lower future study intentions after generating more upward study counterfactuals. There were no other effects on this measure (all $\left.t \mathrm{~s}<1.44, \mathrm{ps}>.15, f^{2}=.02\right)$.

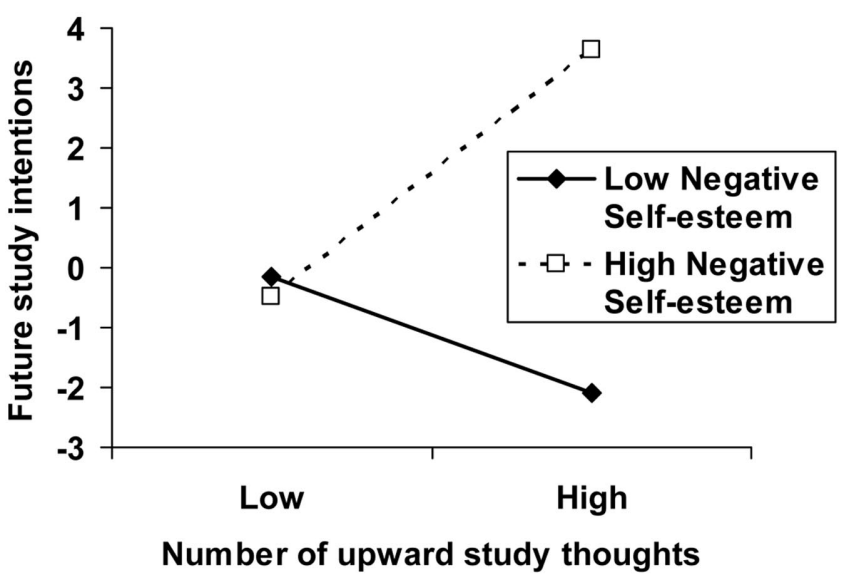

Figure 2. Effect of the Number of Upward Study Thoughts $\times$ Negative Self-Esteem interaction on future study intentions (Study 1).
An additional analysis was conducted to examine whether the effects of upward study thoughts on future study intentions could be explained by attributions to effort. Therefore, the effort attribution measure as well as the interaction of this variable with negative postexam self-esteem was added to the model in a final step. Neither the effort attribution term nor the interaction of effort attributions with negative postexam self-esteem was significant ( $t \mathrm{~s}<1.39, p \mathrm{~s}>.16, f^{2}<.02$ ). The interaction of upward study counterfactual thoughts and negative postexam self-esteem also remained significant, $\beta=.160, t(99)=2.25, p<.05, f^{2}=.06$.

\section{Discussion}

As predicted, a reported lack of study effort increased upward counterfactual thinking about studying. This finding is consistent with past counterfactual research that has shown that individuals are likely to mutate exceptional or abnormal conditions, particularly after a negative outcome (Kahneman \& Miller, 1986; Wells \& Gavanski, 1989), as well as with the predictions of S. J. Sherman and McConnell (1995) that self-handicapping should increase upward counterfactual thinking. Rather than leading to affective contrast effects, upward counterfactual thoughts identifying an unstable factor in the form of a self-handicap excused poor performance and therefore protected self-esteem (see also Covington \& Omelich, 1979; Weiner, 1985).

The second purpose of the study was to examine the consequences of excusing upward counterfactuals for future motivation. Consistent with past research that has shown that upward counterfactuals improve subsequent motivation only when accompanied by negative affect (Markman et al., 2008; Myers \& McCrea, 2008), upward study counterfactual thoughts were associated with higher intentions to study in the future when individuals experienced negative self-esteem as a result of a poor performance. However, as predicted, the reverse effect held for those experiencing less negative self-esteem. Among these individuals, upward study counterfactual thoughts were associated with lower study intentions. In other words, it appears that the preparative effect of upward counterfactual thinking can be undermined or even reversed when these thoughts can serve to excuse a poor performance.

It is also important to note that the effects of upward study counterfactuals were independent of attributions to effort. Thus, although the present findings reveal the usefulness of applying models of attribution (e.g., Weiner, 1985) to counterfactual thinking, they also replicate past research that has shown that causal attribution and counterfactual thinking are independent processes (Mandel, 2003; Mandel \& Lehman, 1996).

\section{Study 2-Manipulating the Availability of a Self- Handicap}

Study 2 was designed to replicate the finding that the availability of a self-handicap increases the generation of upward counterfactuals identifying the handicap following failure and that the generation of these thoughts serves to protect self-esteem. To provide a stronger test of these hypotheses, I experimentally manipulated the presence of a handicap. Consistent with past work examining the reduction of task effort as a self-handicap, participants were told that they would be taking a test of intelligence but 
that the test was not valid unless one spent $10 \mathrm{~min}$ on a practice exam (see also Hirt et al., 1991, 2000). The presence of a handicap was varied by inducing individuals to practice for $10 \mathrm{~min}$ or to not practice at all (see also Brown \& Josephs, 1999; Rhodewalt et al., 1991). A modified induced compliance procedure (cf. Festinger \& Carlsmith, 1959; Smith, 1961) was utilized so that participants felt that their behavior had been freely chosen and that counterfactuals generated about the handicap would identify a controllable behavior. This procedure was important in order to ensure that participants would view the handicap as mutable and that individuals could at least theoretically regret their lack of effort. All participants then completed the actual exam and were given failure feedback. It was predicted that the presence of a handicap (i.e., lack of adequate practice effort) would result in an increase in upward counterfactual thinking, specifically about the handicap itself. The lack of adequate practice should provide a salient reason for poor performance. Furthermore, generating relatively more upward counterfactual thoughts about practice was not expected to predict lower self-esteem in the no-practice (handicap present) condition. In this condition, upward counterfactual thoughts identifying lack of effort should serve as an excuse for failure. Because this excuse was not present in the practice (handicap absent) condition, a negative relationship between upward counterfactual thinking about practice and self-esteem was expected in this condition. As in Study 1, no specific predictions were made for thoughts unrelated to the handicap.

\section{Method}

\section{Participants}

Participants were 125 (64 men and 61 women) Indiana University students in an introductory psychology course. They took part in partial fulfillment of a course requirement. Participants were randomly assigned to one of the two practice conditions.

\section{Materials and Procedure}

Upon entering the lab, participants completed a detailed informed consent statement and were then asked to complete the Rosenberg (1965) Self-Esteem scale while the main experiment was being prepared. They were told that this measure was part of a questionnaire for a colleague at another university. Collected questionnaires were placed in an envelope addressed to this researcher. They were then told that the main experiment would involve taking a nonverbal test of intelligence called the CultureFair Intelligence Test (Cattell \& Cattell, 1961). They were shown four example items, taken from the conditions subtest of the Culture-Fair Intelligence Test. The experimenter led the participants through the first two examples to ensure participants understood the instructions. Participants completed the third and fourth examples on their own. They were told they were correct on the third example and incorrect on the fourth to increase their uncertainty about the exam and make self-handicapping more desirable (cf. Berglas \& Jones, 1978; Hirt et al., 2000; Thompson, 2004).

All participants were told that prior research had indicated that practice ensures that the Culture-Fair Intelligence Test is accurate but that lack of adequate practice can result in a score that is lower than warranted by the person's actual intelligence (cf. Hirt et al.,
1991, 2000). Participants were also told that the researchers were interested in examining the effect of practice on the exam, and so they were asking participants to either complete a set amount of practice problems or to not practice at all. Participants were then randomly assigned to one of two practice conditions.

In the practice condition, participants were told that a computer error had resulted in the experimenter's running too many people in the no-practice condition, and so the participants were asked if they would not mind being in the practice condition (see also Brown \& Josephs, 1999). Once participants had agreed to practice, they were asked again and told that it was their choice to make, in order to reinforce the notion that the choice to practice was their own (cf. Festinger \& Carlsmith, 1959; Smith, 1961).

In the no-practice condition, participants were told that a computer error had resulted in the experimenter's running too many people in the practice condition, and so they were asked if they would not mind being in the no-practice condition. The same procedure to reinforce the notion of free choice was used. In this manner, participants were provided with a viable excuse for any subsequent poor performance.

Immediately following these instructions, participants were asked to what extent they understood the instructions and felt pressured to practice or not practice, responding on a 1 (not at all) to 5 (very much) scale. Following these questions, participants in the practice condition began the practice exam, entering their answers into the computer. They completed 10 practice items without a time limit. Participants in the no-practice condition did not receive any practice items. All participants then began the actual exam, entering their answers into the computer. Following the exam, all participants received failure feedback indicating that they had correctly answered 6 out of 20 problems, placing them in the bottom $35 \%$ of college students. After reading their feedback, they were given instructions concerning the generation of counterfactual thoughts. These instructions, adapted from Roese and Olson (1995c), were as follows:

We are interested in individual differences and how they relate to performance on the nonverbal test. One such difference is the thoughts people have about a test. For example, people often have thoughts like "If only. .." or "At least. .." when thinking about a past performance. People often think about the things that could have happened right before or during such a test, including things they might have done themselves, that could have changed their score on the test.

We would like you to write the thoughts of this type you are having right now about the nonverbal test you just took. For example, you could think, "If only I had _ I I would have done better on the nonverbal test." Alternatively, you could be thinking, "At least happened, or I might have done worse on the nonverbal test.'

Participants were reminded to write thoughts identifying how their performance on the test could have been different. They were then given 5 min to list up to 15 counterfactual thoughts, entering them into the computer.

Participants then completed a state self-esteem and mood measure, as in Study 1. Additional positive self-esteem items were included in order to have a more balanced measure. Participants indicated the extent to which they felt each of the items at that moment, using a 1 (not at all) to 5 (very much) scale.

Participants next indicated to what extent they attributed their performance to their practice effort on a 1 (not at all) to 5 (very 
Table 3

Zero-Order Correlations (Study 2; $N=125$ )

\begin{tabular}{lcccc}
\hline \multicolumn{1}{c}{ Measure } & Upward practice thoughts & Upward miscellaneous thoughts & Effort attributions & Post self-esteem \\
\hline Upward practice thoughts & - & & & \\
Upward miscellaneous thoughts & -.05 & -.14 & - & -.05 \\
Effort attributions & $.29^{* * *}$ & -.13 & 3.07 & 29.73 \\
Post self-esteem & -.03 & 2.42 & 1.36 \\
$M$ & 0.60 & 0.86 & 1.97 & 6.61 \\
$S D$ & & &
\end{tabular}

${ }^{* * *} p<.01$.

much) scale and completed a final manipulation check item concerning to what extent the experimenter had told them that practice is helpful for the nonverbal exam, responding on a 1 (not at all) to 5 (very much) scale. They were then completely debriefed regarding the purpose of the study and need for deception. Specifically, they were told that the feedback they had received was the same for all participants and therefore should not be considered indicative of their actual intelligence.

\section{Results}

\section{Overview}

Initial analyses revealed no gender differences, and so this variable is not considered further. On the basis of correlational and reliability analyses, a nine-item (i.e., shame [reversed], worthless [reversed], incompetent [reversed], inadequate [reversed], smart, effective, resourceful, proud, competent) index of postperformance state self-esteem was created $(\alpha=.84){ }^{2}$ Correlations between the main measures are provided in Table 3. As in Study 1, predictor variables were mean-centered for regression analyses, and simpleslope tests and plotting of predicted scores were conducted at \pm 1 standard deviation from the mean for significant interactions (Aiken \& West, 1991).

\section{Manipulation Checks}

There were no differences between conditions on any of the manipulation checks $\left(t \mathrm{~s}<1.54, p \mathrm{~s}>.12, \eta^{2}<.02\right)$. Individuals reported feeling only somewhat pressured to make the decision to practice or not $(M=3.02, S D=0.92)$. Furthermore, participants reported understanding the instructions $(M=3.62, S D=1.58)$ and correctly recalled that practice had been described as helpful for the exam $(M=3.18, S D=1.22)$.

\section{Counterfactual Thoughts}

Two independent coders identified and classified the counterfactual thoughts by direction (upward or downward) and content (practice or miscellaneous), as in Study 1. For example, the thoughts "If I had had more time to prepare, I might have performed better" and "Maybe practice would have helped" were classified as upward practice thoughts, whereas the thoughts "If I had a better understanding of what the test was asking of me, I would have done better" and "I could have done better on the test if I had concentrated more" were classified as upward miscellaneous thoughts. Interrater agreement was $90 \%(\kappa=.79)$, and disagreements were resolved through discussion. The analyses again centered on the number of upward counterfactual thoughts within the practice $(f=75)$ and miscellaneous $(f=302)$ content categories. ${ }^{3}$ Single-factor (practice condition) analyses of covariance, controlling for Rosenberg Self-Esteem $(\alpha=.93 ; M=53.73$, $S D=12.52)$ as a covariate, were conducted on the number of practice and upward miscellaneous counterfactual thoughts.

For the number of upward practice thoughts, the effect of practice condition was significant, $F(1,121)=42.76, p<.001$, $\eta^{2}=.26$. As predicted, relatively more upward thoughts about practice were generated in the no-practice condition $(M=1.07)$ than in the practice condition $(M=0.17)$. There were no significant effects of practice condition on upward miscellaneous thoughts, $F(1,121)=1.59, p=.21, \eta^{2}=.01$. There were no effects of Rosenberg Self-Esteem on either thought category $\left(F_{\mathrm{s}}<\right.$ $\left.1.12, n s, \eta^{2}<.01\right)$.

\section{Attribution to Effort}

The postperformance self-esteem index was regressed onto the following model: Rosenberg Self-Esteem scores, practice condition (dummy coding: $1=$ practice condition, $0=$ no-practice condition), number of upward practice thoughts, number of upward miscellaneous thoughts, and the interactions of these two counterfactual thought categories with practice condition.

Although the zero-order correlation between upward practice counterfactuals and effort attributions was positive and significant,

\footnotetext{
${ }^{2}$ In addition, indices of worry (i.e., scared, nervous, afraid, fearful, panic, and worried; $\alpha=.85$ ), disappointment (i.e., disappointed, discouraged, upset, pessimistic, irritable, and insecure; $\alpha=.83$ ) and positive mood (i.e., enthusiastic, inspired, delighted, hopeful, pleased, optimistic, active, excited, determined, satisfied, interested; $\alpha=.92$ ) were created. Regressing the worry index onto the same regression model as the one used to assess effects on postexam self-esteem revealed effects of Rosenberg Self-Esteem scores, $\beta=-.243, t(115)=2.63, p<.05, f^{2}=.06$, but no other effects $\left(t \mathrm{~s}<1.36, p \mathrm{~s}>.17, f^{2}<.02\right)$. The practice-condition effect approached significance on the positive mood index, $\beta=-.241, t(115)=$ $1.98, p=.05, f^{2}=.03$, indicating that individuals reported more positive affect in the no-practice condition. There were no other significant effects on positive mood $\left(t \mathrm{~s}<1.48, p \mathrm{~s}>.14, f^{2}<.02\right.$ ). Finally, there were no effects on the disappointment index $\left(t \mathrm{~s}<1.67, p \mathrm{~s}>.09, f^{2}<.03\right)$.

${ }^{3}$ As in Study 1, including downward thoughts in the analyses either as a separate variable or by creating an overall index of the direction of counterfactuals did not alter the results presented here. Higher numbers of miscellaneous downward thoughts predicted decreased worry and disappointment, but there were no other effects of downward thoughts.
} 
only the practice-condition term predicted effort attributions in this regression model, $\beta=-.424, t(115)=3.83, p<.001, f^{2}=.11$. Participants made more attributions to effort in the no-practice condition than they did in the practice condition. There were no other significant effects $\left(t \mathrm{~s}<1.81, p \mathrm{~s}>.07, f^{2}<.03\right)$.

\section{Postperformance Self-Esteem}

The postperformance self-esteem index was regressed onto the following model: Rosenberg Self-Esteem scores, practice condition (dummy coding: 1 = practice condition, $0=$ no-practice condition), number of upward practice thoughts, number of upward miscellaneous thoughts, and the interactions of these two counterfactual thought categories with practice condition. Over and above the effect of Rosenberg Self-Esteem scores, $\beta=.151$, $t(115)=1.64, p=.10, f^{2}=.03$, the Practice $\times$ Number of Upward Practice Thoughts interaction was significant, $\beta=-.297$, $t(115)=2.36, p<.05, f^{2}=.05$ (see Figure 3 ). Simple-slope tests conducted while controlling for Rosenberg Self-Esteem scores revealed a significant effect of upward practice thoughts in the practice condition ( simple-slope $=-5.38$ ), $t(117)=2.53, p<$ $.05, f^{2}=.05,95 \% \mathrm{CI}:-9.58$ to -1.17 , but not in the no-practice condition (simple-slope $=0.59, t<1, n s, f^{2}=.00,95 \% \mathrm{CI}$ : -1.09 to 2.27 ). Thus, generating more upward thoughts about practice predicted lower self-esteem only in the practice condition. There were no effects of the miscellaneous counterfactual thoughts $\left(t \mathrm{~s}<1, n s, f^{2}=.00\right)$.

An additional analysis was conducted to examine whether the effects of upward practice thoughts on postexam self-esteem could be explained by attributions to effort. Therefore, the effortattribution measure as well as the interaction of this variable with practice condition was added to the model. The Practice $\times$ Effort Attribution term was indeed a significant predictor of postexam self-esteem, $\beta=-.310, t(113)=2.23, p<.05, f^{2}=.04$, indicating that individuals reported less positive postexam selfesteem in the practice condition (but not in the no-practice condition) when they attributed their performance to effort. More importantly, however, the Practice $\times$ Number of Upward Practice

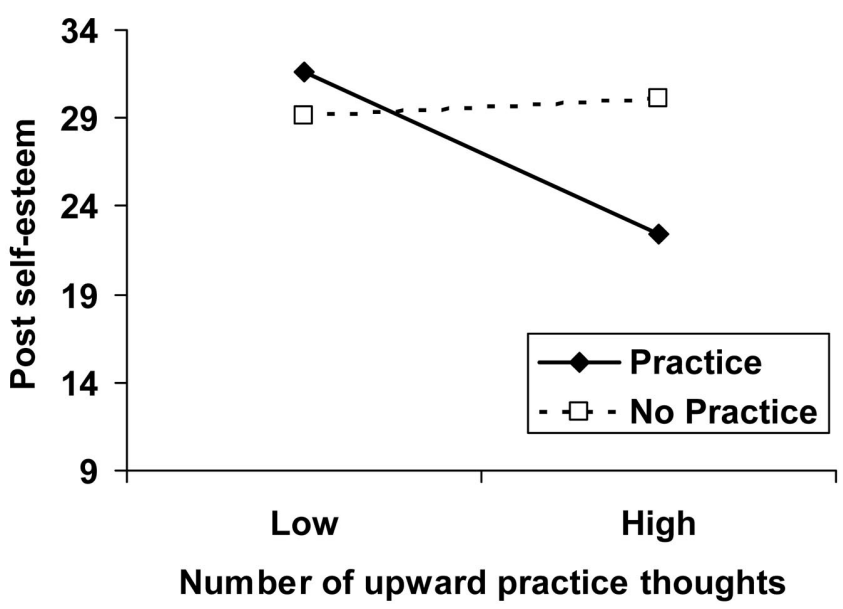

Figure 3. Effect of the Number of Upward Practice Thoughts $\times$ Practice Condition interaction on postperformance self-esteem (Study 2).
Thoughts interaction remained significant, $\beta=-.295, t(113)=$ $2.38, p<.05, f^{2}=.05$.

\section{Discussion}

The presence of a handicap in the form of insufficient practice resulted in increased upward counterfactual thinking about the handicap. Furthermore, higher numbers of upward practice thoughts predicted more negative self-esteem in the practice condition, consistent with past work showing affective contrast effects of upward counterfactual thinking (Boninger et al., 1994; Markman et al., 1993; Roese, 1994). However, the number of upward practice thoughts was unrelated to postexam self-esteem in the no-practice condition. Thus, upward counterfactual thoughts identifying an existing handicap predicted maintained self-esteem. These findings are consistent with models of attribution (e.g., Weiner, 1985) predicting that attributing a failure to an unstable cause protects self-esteem. However, replicating Study 1, the effects of counterfactual thoughts were not accounted for by attributions to effort, suggesting counterfactuals are independent of attribution processes (see also Mandel, 2003; Mandel \& Lehman, 1996).

\section{Study 3-Manipulating Counterfactual Direction}

Studies 1 and 2 demonstrated that upward counterfactual thoughts pointing to an available self-handicap predicted maintained self-esteem after a failure. Furthermore, excusing upward counterfactuals predicted reduced future study intentions. However, due to the correlational nature of these findings, the causal effect of these thoughts on self-esteem and subsequent motivation is still unclear. Furthermore, these studies did not allow comparison to a control condition in which participants did not consider counterfactuals. To provide stronger evidence for the claim that upward counterfactual thoughts protect self-esteem when pointing to a self-handicap, the direction of counterfactual thinking was manipulated in Study 3. Specifically, participants were induced to practice inadequately for an exam and subsequently told that they had failed, as in Study 2. They were then exposed to downward counterfactuals, upward counterfactuals, or were assigned to a no-counterfactual control condition, and completed a state selfesteem measure. It was predicted that, in the presence of a handicap, individuals would report more positive self-esteem after considering upward counterfactuals pointing to the handicap as having prevented better performance, relative to those in the control condition, and no different or perhaps more positive than those considering downward counterfactuals.

A second purpose of the study was to replicate the finding from Study 1 that upward counterfactuals predict lower subsequent preparation intentions when accompanied by more positive selfesteem. To provide stronger evidence for these effects on subsequent motivation to improve, participants in the present study were given a surprise opportunity to practice for a second version of the exam. The number of items attempted and the time spent practicing were recorded to provide a behavioral measure of subsequent preparation. It was predicted that individuals would practice less in the upward counterfactual condition than they would in the control and downward counterfactual conditions, as these thoughts would 
serve to excuse the poor performance by identifying the selfhandicap as having prevented a better score.

The surprise nature of the subsequent exam was important. A potential drawback of the design of Study 1 was that participants knew that they would have the opportunity to take a similar test again in the future. Outcomes that can be changed in the future more often lead to affective assimilation for counterfactual thinking (Boninger et al., 1994; McMullen \& Markman, 2002). An alternative explanation for the self-esteem findings in Study 1 then could be that individuals generating more upward counterfactual thoughts felt relieved because they knew they could study more in the future and improve their performance. Of course, this contradicts the finding that these same individuals intended to study less in the future. Nonetheless, it is important to rule out this possible explanation by demonstrating that participants would show the same effects for self-esteem and preparatory behavior when they were initially unaware that a second performance opportunity would arise.

Study 3 sought to demonstrate these effects with a different type of academic performance, specifically a mathematics test. Furthermore, the evaluative threat of the performance was increased by placing participants under conditions of public self-focus via a closed-circuit camera. Previous research has shown that such conditions increase the likelihood of self-handicapping behavior (Hirt et al., 2000).

\section{Method}

\section{Participants and Design}

Participants were 73 (39 women, 34 men) University of Konstanz students, recruited in return for research credit or $€ 5$ payment. Seven participants were excluded for reporting suspicion about the purpose of the study or the negative feedback, leaving 66 (34 women, 32 men) participants in the study. They were randomly assigned to one of three counterfactual conditions (upward counterfactual, downward counterfactual, or no-counterfactual control).

\section{Materials and Procedure}

Participants first completed the Rosenberg Self-Esteem scale as part of a prescreening questionnaire prior to participation in the experiment using a scale from 0 (not at all) to 5 (very much). Participants were told this questionnaire was required for all those participating in studies in the Social and Motivational Psychology department. Questionnaires were identified only by a unique code.

Participants arrived individually at the laboratory and were told the experiment dealt with performance on a mathematics test. They were told that prior research had shown that individuals respond more honestly when they are observed, and that for this reason, they would be observed via a video camera connection to the experimenter's computer monitor (cf. Hirt et al., 2000). Participants were shown that the camera and the video display were on and working and then completed a consent statement agreeing to be involved in the study.

The test was described as measuring not only math ability but also the ability to solve problems logically. Participants were told the experimenters were interested in individual differences in performance on this test, and so they would also be completing personality measures. They were then told that one disadvantage of the math test was that it was not predictive of actual ability if test takers had not completed a short practice test in order to "warmup" (cf. Hirt et al., 1991, 2000). They were told that this effect was being further evaluated and that therefore they would be assigned to practice either the entire recommended 10-min period or only a 2 -min period. These instructions were repeated through a test of understanding to ensure that participants had paid attention. As in Study 2, the experimenter explained that a previous programming error had resulted in assigning everyone to the practice condition, and therefore there were not enough people who had insufficiently practiced. The experimenter asked all participants to be in the low-practice condition, and this choice was reinforced through additional questioning.

Participants then completed the 2-min practice session and began the actual 20-item exam. The exam was adapted from the mathematics section of the I-S-T 2000R (Amthauer, Brocke, Liepmann, \& Beauducel, 2001). After the completion of the exam, participants were informed that they had answered 11 out of 20 correct, placing them in the 35 th percentile of university students. Participants were then told that they would read 10 statements made by previous participants about their performance on the exam. They were asked to carefully read the statements and relate them to their own performance on the math test. They were then randomly assigned to read one of three different sets of statements. In the upward counterfactual condition, participants read 5 counterfactual statements indicating that a greater amount of practice would have improved their performance (e.g., "If I had practiced more, I would have done better") and 5 neutral statements (e.g., "The test was interesting"). In the downward counterfactual condition, participants read 5 downward counterfactual statements indicating that less practice would have undermined their performance (e.g., "If I had practiced less, I would have done worse") and the 5 neutral statements. A mix of neutral and counterfactual statements was utilized in order to reduce suspicion on the part of participants. In the control condition, participants read 10 neutral statements. In all conditions, the 10 statements were each presented for $30 \mathrm{~s}$, and the order of the statements was randomized.

Following exposure to the counterfactual statements, participants completed the state self-esteem measure. As in Study 2, they indicated to what extent they felt each of the items at that moment using a 1 (not at all) to 7 (very much) scale. After completing this measure, participants were told that they would be completing a second version of the math test. There had been no mention of the second test prior to this point. They were told that in this second version of the test, speed of response was considered such that it was important to be fast as well as correct. They were told that the second version of the test was also influenced by practice but that because of the speed component, the amount of practice they had on the previous version had no real effect on this second version. Therefore, they were told it was important to again practice $10 \mathrm{~min}$ in order to make the scores of the test a true measure of their mathematical ability. Participants could decide how much or how little they practiced for the test. After each answered item, participants could decide whether to continue or quit the practice session. Practice time and the number of items completed were recorded. 
Finally, participants were told they had been assigned to a control condition in which it was not necessary to complete the second math test. They were next asked to answer several questions concerning the test. First, they were asked to recall the instructions they were given concerning the effects of practice. They indicated whether the experimenter had said that practice affected the test on a 1 (no effect) to 5 (strong effect) scale. They were also asked whether they believed practice affects the test using the same scale. Next, participants were asked how important it was for them to perform well on the test using a 1 (not at all) to 5 (very important) scale and whether the test was valid using a 1 (not at all) to 5 (very valid) scale. They were then fully debriefed (including being told the feedback was the same for all participants) and were given the opportunity to see their actual exam performance.

\section{Results}

\section{Overview}

To eliminate skewness in the practice measures, practice time $(M=225.70 \mathrm{~s}, S D=220.19)$ and number of questions completed $(M=7.65, S D=6.97)$ were square-root-transformed. The two measures were highly correlated $(r=.91)$. Consistent with past work (see Hirt et al., 1991, 2000), these measures were standardized and summed $(\alpha=.95)$. The nine postperformance self-esteem items (worthless [reversed], inadequate [reversed], shame [reversed], dumb [reversed], unable [reversed], proud, competence, resourceful, capable) were also combined into a single measure $(\alpha=.70)$. Initial analyses revealed no significant effects of gender, and so this variable was dropped from further consideration. Analyses on postperformance self-esteem and practice effort were conducted after controlling for Rosenberg Self-Esteem scores $(\alpha=.85, M=37.67, S D=7.87)$ as well as perceived importance and validity of the exam.

\section{Manipulation Checks}

There were no significant effects on any of the manipulation checks (all $F_{\mathrm{s}}<2.07, p \mathrm{~s}>.13, \eta^{2}<.07$ ). Participants correctly recalled the practice instructions $(M=4.70, S D=0.78)$, believed that amount of practice had an effect on performance on the test $(M=4.03, S D=1.04)$, reported that it was somewhat important for them to do well on the exam $(M=2.86, S D=1.25)$, and that the exam was a valid measure of math ability $(M=3.29, S D=$ 1.16).

\section{Postperformance Self-Esteem}

Regressing the postperformance self-esteem index on Rosenberg Self-Esteem scores and perceived importance and validity of the exam revealed an effect of Rosenberg Self-Esteem, $\beta=.398$, $t(62)=3.41, p<.01, f^{2}=.16$. There were no effects of perceived importance or validity of the exam $\left(t \mathrm{~s}<1, n s, f^{2}=.00\right)$. Planned comparisons were then conducted on the postperformance selfesteem residual scores (see Table 4). As predicted, those in the upward counterfactual condition reported more positive selfesteem than did those in the control condition, $t(63)=2.49, p<$ $.05, \eta^{2}=.09$. The difference between the upward and downward
Table 4

Study 3 Results

\begin{tabular}{lrrr}
\hline \multicolumn{1}{c}{ Measure } & $\begin{array}{r}\text { Upward } \\
(n=24)\end{array}$ & $\begin{array}{c}\text { Downward } \\
(n=20)\end{array}$ & $\begin{array}{r}\text { Control } \\
(n=22)\end{array}$ \\
\hline Post self-esteem (raw scores) & & & \\
$\quad M$ & 34.96 & 34.30 & 32.23 \\
$S D$ & 3.14 & 3.59 & 5.40 \\
Post self-esteem (residual scores) & & & \\
$\quad M$ & 1.32 & 0.26 & -1.46 \\
$S D$ & 2.90 & 2.87 & 5.10 \\
Practice index (raw scores) & & & \\
$M$ & -0.54 & 0.65 & 0.04 \\
$S D$ & 2.02 & 1.77 & 1.90 \\
Practice index (residual scores) & & & \\
$M$ & -0.66 & 0.74 & 0.05 \\
$S D$ & 1.93 & 1.73 & 1.75 \\
\hline
\end{tabular}

counterfactual conditions was not significant, $t(63)=1.13, p=$ $.26, \eta^{2}=.02$.

\section{Subsequent Preparation}

Regressing the practice index on Rosenberg Self-Esteem scores and perceived importance and validity of the exam revealed only a nonsignificant effect of importance of the exam, $\beta=.240$, $t(62)=1.91, p=.06, f^{2}=.06$. There were no other effects $(t \mathrm{~s}<$ $\left.1, n s, f^{2}<.02\right)$. Planned comparisons were conducted on the practice index residual scores (see Table 4). Those in the upward counterfactual condition practiced significantly less than did those in the downward counterfactual condition, $t(63)=2.56, p<.05$, $\eta^{2}=.09 .{ }^{4}$ The difference between the upward counterfactual and control conditions was not significant, $t(63)=1.33, p=.19, \eta^{2}=$ .03 .

\section{Discussion}

Replicating the prior studies, exposure to upward counterfactual thoughts pointing to a self-handicap mitigated the negative impact of a failure on self-esteem relative to exposure to a set of neutral thoughts. Downward counterfactuals also appeared to have a positive impact on self-esteem, albeit somewhat weaker than the upward counterfactuals had. Study 3 extended the prior studies by

\footnotetext{
${ }^{4}$ Given that the second exam was said to assess speed as well as correctness, it could be that reduced practice in the upward counterfactual thought condition was due to increased speed of practice in this condition. Planned comparisons were therefore conducted on the speed of practice (those not practicing at all were considered missing), after controlling for Rosenberg Self-Esteem scores and perceived importance and validity of the exam. There was a significant effect of test importance, $\beta=-.313$, $t(56)=2.38, p<.05, f^{2}=.09$, such that those perceiving the test as more important practiced more slowly. There were no effects of Rosenberg Self-Esteem or test validity on speed scores $(t s<1, n s)$. More importantly, there were no differences between conditions for either the unstandardized residual scores or the raw speed scores (all $t \mathrm{~s}<1.68, p \mathrm{~s}>$.09). Indeed, practice speed was actually nonsignificantly slower in the upward counterfactual condition ( $M=2.76$ items per minute) compared to the control condition ( $M=4.09$ items per minute). Thus, reduced practice effort in the upward counterfactual condition was not due to differences in speed of practice.
} 
demonstrating the causal effects of counterfactual content on subsequent self-esteem. It is also important to note that these effects occurred despite participants not being aware that they would be able to repeat the performance. Previous research has shown that upward counterfactuals result in less negative affect when the event is repeatable (Boninger et al., 1994; McMullen \& Markman, 2002). Because participants were initially unaware of the opportunity to practice for an additional exam, the more positive selfesteem reported by participants in the upward counterfactual condition is unlikely to be due to participants feeling more prepared.

This interpretation is also reinforced by the finding that the preparative function of upward counterfactual thinking was eliminated when these thoughts could serve as an excuse. Rather than demonstrating increased motivation to practice, individuals practiced significantly less for the second exam after exposure to the upward counterfactual thoughts than they did after exposure to downward counterfactuals. Indeed, examining the practice measures more closely reveals that 5 participants in the upward counterfactual condition failed to practice a single item, whereas only 1 participant in the downward and control conditions combined failed to practice. Thus, the effects on future study intentions observed in Study 1 were replicated using an experimental manipulation of counterfactual direction and measuring actual practice behavior. The benefits of counterfactual thinking for preparation and motivation appear to be dependent on whether the thought serves a self-protective or mood-maintaining function for the individual rather than on the direction (upward or downward) of the thought. When upward counterfactual thoughts do not result in dissatisfaction with the performance, they no longer have positive benefits for future motivation (see also Markman \& McMullen, 2003; Myers \& McCrea, 2008).

\section{Study 4-Manipulating Counterfactual Content}

The consequences of upward counterfactuals identifying a selfhandicap for self-esteem and subsequent motivation have thus far been explained with reference to classic models of attribution (Covington \& Omelich, 1979; Weiner, 1985), as well as past findings in the self-handicapping literature (McCrea \& Hirt, 2001; Rhodewalt et al., 1991) that have proposed that attributing a poor performance to an unstable cause (such as a self-handicap) serves to protect self-esteem. To test this explanation more directly, in Study 4, I manipulated whether participants were exposed to upward counterfactuals suggesting that either a self-handicap (i.e., an unstable factor) or a lack of ability (i.e., a stable factor) was to blame for a poor math performance. A second goal of the present study was to replicate the previous findings with a different type of self-handicap. Rather than practicing insufficiently, participants were induced to listen to distracting noises while completing the math test (Rhodewalt et al., 1991; Shepperd \& Arkin, 1989b). It was expected that upward counterfactual thinking would protect self-esteem only when the thoughts pointed to noise as having prevented a better score on the math test.

Furthermore, it was predicted that motivation to improve on a subsequent test would be lower when poor performance was excused by upward counterfactuals. To test this notion, participants were asked to select the level of distraction they would experience during a surprise second version of the math test. It was expected that individuals exposed to upward counterfactual thoughts suggesting that the noise was to blame for their poor performance would be more likely to listen to distracting noise during the second math test than would those exposed to counterfactual thoughts suggesting that their own lack of ability was to blame. Based on pretesting and past findings demonstrating that men are more likely than women to self-handicap by placing themselves in distracting environments (Rhodewalt, 1990; Rhodewalt et al., 1991; Shepperd \& Arkin, 1989b), only men participated in the present study.

\section{Method}

\section{Participants and Design}

Participants were 40 male University of Konstanz students. Four participants expressed suspicion of the procedure and were therefore excluded. Two additional participants were excluded due to an equipment malfunction causing the distracting noise not to play properly. The remaining 34 participants were randomly assigned to one of three (handicap, ability, or control) counterfactual conditions.

\section{Procedure}

Participants again completed the Rosenberg Self-Esteem scale as part of a prescreening measure prior to the experimental session. Upon entering the laboratory for the experimental session, participants were told the study dealt with math performance and environmental noise, and they completed a consent form as in prior studies. They were informed they would be taking a math test and that performance on this test could be affected by different types of sounds (see also Rhodewalt et al., 1991; Shepperd \& Arkin, 1989b). They were told that the investigators wished to further examine this finding and that therefore they would be asked to listen to either performance-enhancing or performance-impairing noises during the test. As in prior studies, participants were told a computer error had resulted in too many participants being assigned to listen to the helpful noises. For this reason, they were asked if they would listen to the distracting music, and this choice was reinforced. They then were asked to wear a pair of headphones and complete a 20-item math test (again adapted from Amthauer et al., 2001) while listening to a sampling of annoying traffic and construction noises. The noises were presented at a comfortable listening volume (approximately $45-50 \mathrm{~dB}$ ), at a level that is rated as "highly annoying" by less than $5 \%$ of individuals and far below the standard pain threshold of $110 \mathrm{~dB}$ (see Algom, Raphaeli, \& Cohen-Raz, 1986; Ouis, 2001, for reviews). The noises were thus designed to be distracting rather than stressful.

Following the exam, participants received failure feedback and were assigned to one of the three counterfactual conditions. They read 10 statements supposedly written by a previous participant. Those in the handicap condition read 5 thoughts indicating that the person's performance could have been improved if (s)he had been less distracted or had chosen a less impairing noise selection (e.g., "If only I had listened to more neutral noises, I would have achieved a better result") and 5 neutral statements. Participants in the ability condition read 5 thoughts indicating that the person's performance could have been improved if (s)he was better at math or had made fewer mistakes (e.g., "My performance would maybe 
have been better if I was better at math") and 5 neutral statements. Those in the control condition read 10 neutral statements that did not indicate how the person's performance could have been different (e.g., "I am surprised about my score"). Each thought was presented for $30 \mathrm{~s}$ and participants were asked to relate the thought to their own performance on the math test.

Following the counterfactual manipulation, participants completed the postperformance self-esteem measure, as in prior studies. They were then told that they would be given a chance to complete a different version of the exam in which speed is factored into the scoring. As in Study 3, there had been no mention of this test prior to this point. They were told that for this second version of the exam, they could choose the level of distraction of the noise they would hear during the test using a scale from 1 (performance hindering) to 7 (performance facilitating). After this selection was made, participants were told they had been assigned to a control condition and would not need to complete the second test. They completed manipulation checks concerning whether noise could affect their math performance, as well as the importance and the validity of the test as in Study 3, and they were then fully debriefed as in prior studies and given the opportunity to see their actual exam score.

\section{Results}

\section{Overview}

As in previous studies, the postperformance self-esteem items (worthless [reversed], inadequate [reversed], shame [reversed], dumb [reversed], unable [reversed], proud, competence, resourceful, capable) were combined into a single measure $(\alpha=.69)$. Analyses on postperformance self-esteem and choice of noise were conducted after controlling for Rosenberg Self-Esteem scores $(\alpha=.81, M=40.03, S D=6.85)$ as well as perceived importance and validity of the exam.

\section{Manipulation Checks}

One-way analyses of variance conducted on each of the manipulation checks revealed no differences between conditions (all $\left.F \mathrm{~s}<1.33, p \mathrm{~s}>.28, \eta^{2}<.09\right)$. Participants appeared to believe the test was a reasonably valid measure of math ability $(M=2.97$, $S D=1.03)$ and also felt it was important for them to do well $(M=$ $3.56, S D=0.96)$. Furthermore, they believed that the noises could affect their performance $(M=3.82, S D=0.90)$.

\section{Postperformance Self-Esteem}

Regressing the postperformance self-esteem index on Rosenberg Self-Esteem scores and perceived importance and validity of the exam revealed an effect of Rosenberg Self-Esteem, $\beta=.545$, $t(30)=3.70, p<.01, f^{2}=.31$. There were no effects of perceived validity and importance of the exam $\left(t \mathrm{~s}<1.69, \mathrm{ps}>.10, f^{2}<\right.$ .09). Planned comparisons on the residual scores revealed that participants reported more positive self-esteem in the handicap condition than they did in the control condition, $t(31)=2.10, p<$ $.05, \eta^{2}=.12$ (see Table 5). There was also a nonsignificant trend for participants to report more positive self-esteem in the handicap than in the ability condition, $t(31)=1.80, p=.08, \eta^{2}=.09$.
Table 5

Study 4 Results

\begin{tabular}{lrrr}
\hline \multicolumn{1}{c}{ Measure } & $\begin{array}{r}\text { Handicap } \\
(n=12)\end{array}$ & $\begin{array}{c}\text { Ability } \\
(n=12)\end{array}$ & $\begin{array}{r}\text { Control } \\
(n=10)\end{array}$ \\
\hline $\begin{array}{r}\text { Post self-esteem (raw scores) } \\
M\end{array}$ & 37.17 & 35.33 & 34.80 \\
$\quad S D$ & 3.13 & 3.34 & 5.39 \\
Post self-esteem (residual scores) & & & \\
$\quad M$ & 1.58 & -0.63 & -1.14 \\
$\quad S D$ & 2.40 & 2.53 & 4.07 \\
Noise choice (raw scores) & & & \\
$\quad M$ & 5.00 & 6.33 & 5.50 \\
$S D$ & 2.22 & 1.07 & 1.43 \\
Noise choice (residual scores) & & & \\
$M$ & -0.64 & 0.62 & 0.04 \\
$S D$ & 1.71 & 1.31 & 1.08 \\
\hline
\end{tabular}

\section{Choice of Noise}

Regressing the choice of noise on Rosenberg Self-Esteem scores and perceived importance and validity of the exam revealed an effect of importance of the exam, $\beta=.512, t(30)=2.99, p<.01$, $f^{2}=.23$, indicating that those perceiving the test as more important selected more helpful noise. There were no effects of selfesteem scores and perceived validity of the exam ( $t \mathrm{~s}<1, n s, f^{2}=$ .00). Planned comparisons on the residual scores revealed that participants selected less helpful noise in the handicap condition relative to the ability condition, $t(31)=2.19, p<.05, \eta^{2}=.13$ (see Table 5). There was no difference between the control and handicap conditions, $t(31)=1.13, p>.26, \eta^{2}=.04$.

\section{Discussion}

Replicating the previous studies, upward counterfactual thoughts identifying an available handicap protected self-esteem after failure relative to a control condition. In contrast, when upward counterfactuals identified a lack of ability or mistakes as having prevented better performance, self-esteem was equivalent to levels reported in the control condition. These findings thus directly support the contention that counterfactuals identifying relatively more unstable factors as having prevented a better outcome serve to protect self-esteem, consistent with past attribution and self-handicapping research (e.g., Covington \& Omelich, 1979; Feick \& Rhodewalt, 1997; McCrea \& Hirt, 2001; Rhodewalt et al., 1991; Weiner, 1985). Furthermore, when upward counterfactuals identified a handicap, motivation to improve (as measured by the selection of more helpful noise) was reduced. This latter finding is particularly noteworthy given that only these thoughts contained the information that more helpful noise would have improved performance. Thus, the benefits of counterfactual thinking for preparation in this study seemed to be driven more by motivational considerations than by the identification of a useful strategy.

\section{Study 5-Reduced Motivation or Increased Self- Handicapping?}

A remaining question concerns the source of the reduced preparative effects observed when upward counterfactuals concern a self-handicap. Thus far, it has been argued that this effect occurs 
because excusing failure leaves the individual relatively more satisfied with the performance and thus less motivated to improve in the future. A growing literature has demonstrated that counterfactuals benefit future performance only when accompanied by negative affect (Markman \& McMullen, 2003; Markman et al., 2008; McMullen \& Markman, 2000; Myers \& McCrea, 2008). However, it is possible that the effects in the present studies are rather due to an increase in the motivation to self-handicap on the subsequent task. ${ }^{5}$ One could argue that counterfactuals mentioning the self-handicap make this self-protective strategy more cognitively accessible, consistent with past work demonstrating situational priming of goals (Bargh, Gollwitzer, Lee-Chai, Barndollar, $\&$ Troetschel, 2001). Alternatively, because the counterfactual mentioning the self-handicap excuses poor performance, the individual may continue to positively evaluate his or her ability and thus is motivated to continue protecting this self-concept by selfhandicapping on subsequent tasks. In contrast, those who have not excused a poor performance would already suffer from lowered self-esteem and thus have nothing left to protect. Selfhandicapping is reduced after failure feedback (Berglas \& Jones, 1978; Higgins \& Harris, 1988; Thompson, 2004) and is generally construed as an attempt to protect positive yet fragile self-views (Harris \& Snyder, 1986; Jones \& Berglas, 1978). Study 5 was therefore designed to examine whether decreased task motivation or increased self-handicapping motivation better accounts for the present effects. Participants were induced to practice insufficiently and assigned to consider either handicap-related upward counterfactual thoughts or control thoughts, as in Study 3. However, rather than assessing desire to engage in a behavior that could undermine performance (e.g., reduced subsequent practice or listening to distracting noises), participants' actual effort and performance on the task was measured. To assess motivation to self-handicap, participants were told that performance on the second exam was undermined by high stress levels and that they would therefore be asked to complete a stress measure. A number of previous studies have shown that individuals will claim stress as a handicap, and both men and women are willing to self-handicap in this manner (Hendrix \& Hirt, 2008; Hirt et al., 1991; McCrea \& Hirt, 2001). Thus, if the self-handicapping account is correct, exposure to the self-handicap-related upward counterfactuals should result in higher stress reporting but have no effect on task motivation, compared to control thoughts. In contrast, if the motivation account is correct, there should be no effects of counterfactual thought on stress reporting, but task effort and performance should be reduced after exposure to the self-handicap-related upward counterfactuals.

\section{Method}

\section{Participants and Design}

Participants were 28 (14 women, 14 men) University of Konstanz students. They either were paid $€ 5$ or received credit in return for participation and were randomly assigned to one of two thought conditions (handicap vs. control) in a between-subjects design.

\section{Procedure}

The design was adapted from Study 3. The observation of participants via camera was eliminated given that this manipula- tion proved unnecessary in Study 4. Participants completed the Rosenberg Self-Esteem inventory as part of a prescreening measure. Upon arrival to the laboratory, they were told the experiment involved factors influencing math performance and completed a consent form. After receiving the practice instructions, participants completed an initial 2-min (insufficient) practice session, the first math exam, and received failure feedback. Following exposure to either the handicap-related (i.e., lack of practice) upward counterfactual thoughts or the control thoughts, participants were given instructions concerning a surprise second math exam. They were told that the second exam includes a time component and therefore is strongly affected by one's current ability to concentrate. Individuals experiencing stress in their lives can become distracted and, as a result, not perform as well. Participants were therefore asked to complete a 32-item stress inventory (adapted from Kanner, Coyne, Schaeffer, \& Lazarus, 1981). This measure served as an assessment of self-handicapping (see also Hendrix \& Hirt, 2008; Hirt et al., 1991).

Following the stress inventory, participants began the second math exam. The number of items attempted and the number correctly answered in a 4-min period were recorded. Participants then completed manipulation checks as in previous studies.

\section{Results and Discussion}

Initial analyses revealed no effects of gender, importance of the test $(M=3.78, S D=1.05)$, or perceived validity of the exam $(M=3.44, S D=0.89)$, and so these variables are not discussed further. Participants successfully remembered the instructions that stress $(M=4.41, S D=1.01)$ and lack of practice $(M=4.70$, $S D=0.72)$ undermined performance. Given the specific directional hypotheses, one-tailed $t$-tests were conducted on the dependent measures. Means, standard deviations, and inferential statistics for these analyses are presented in Table 6.

\section{Stress Reporting}

Responses to the stress inventory items were summed $(\alpha=.87)$. There were no significant differences in overall stress scores (see Table 6). Thus, the self-handicapping account was not supported.

\section{Task Effort and Performance}

Participants in the control condition attempted, and correctly answered, significantly more items in the 4-min period than did those in the handicap-related counterfactual condition (see Table 6). Furthermore, as a proportion of items attempted, participants in the control condition outperformed those in the handicap-related counterfactual condition (see Table 6).

In summary, the results strongly support the conclusion that considering counterfactuals about a self-handicap reduces motivation to improve on subsequent tasks. There did not appear to be any evidence that these thoughts increased the desire to selfhandicap. Future researchers should continue to examine this question however. Certainly, it can be argued that reduced concern with success might increase the attractiveness of self-handicaps (see also Oleson, Poehlmann, Yost, Lynch, \& Arkin, 2000). Further-

\footnotetext{
${ }^{5}$ I thank Keith Markman for making this suggestion.
} 
Table 6

Study 5 Results

\begin{tabular}{|c|c|c|c|c|}
\hline Condition & Stress index & $\begin{array}{l}\text { Number of } \\
\text { items } \\
\text { attempted }\end{array}$ & $\begin{array}{r}\text { Number } \\
\text { correct }\end{array}$ & $\begin{array}{l}\text { Percent } \\
\text { correct }\end{array}$ \\
\hline \multicolumn{5}{|c|}{ Handicap $(n=13)$} \\
\hline$M$ & 60.23 & 8.85 & 5.62 & $62.1 \%$ \\
\hline$S D$ & 12.37 & 3.91 & 3.04 & $18.5 \%$ \\
\hline \multicolumn{5}{|c|}{ Control $(n=15)$} \\
\hline$M$ & 55.33 & 11.20 & 8.20 & $74.3 \%$ \\
\hline$S D$ & 12.30 & 2.81 & 2.18 & $16.0 \%$ \\
\hline$t$ & 1.05 & 1.85 & 2.61 & 1.87 \\
\hline$p$ (one-tailed) & .15 & $<.05$ & $<.01$ & $<.05$ \\
\hline$\eta^{2}$ & .04 & .11 & .21 & .12 \\
\hline
\end{tabular}

more, the present studies only examined the consequences of upward counterfactual thoughts following a failure. Selfhandicapping tends to be increased when one feels uncertain about a prior success rather than a prior failure (Berglas \& Jones, 1978; Thompson, 2004). The notion that counterfactuals motivate individuals to self-handicap would perhaps find support when these thoughts have been made after a successful performance, particularly for downward counterfactuals indicating that a worse performance could have been obtained.

\section{General Discussion}

The present studies sought to demonstrate that upward counterfactual thoughts can serve to excuse a poor performance (see also S. J. Sherman \& McConnell, 1995). This proposed effect of counterfactual thinking was examined in the context of selfhandicapping. It was predicted and found that (a) the presence of a self-handicap increases the availability of upward counterfactual thoughts, (b) upward counterfactual thoughts indicating that a self-handicap prevented a better outcome result in more positive self-esteem following failure, and (c) these same thoughts reduce motivation to adequately prepare for and do well on an upcoming performance. Furthermore, evidence for these relationships was observed in laboratory and field settings, with different types of academic tests, for both intended and actual behavior, and with both spontaneously generated and experimentally manipulated counterfactuals.

\section{Counterfactual Thinking and Self-Protection}

Counterfactual thinking has been linked in numerous studies to causal reasoning (Branscombe et al., 2003; Mandel, 2003; Mandel \& Lehman, 1996; Wells \& Gavanski, 1989). Furthermore, past research has shown that the locus of counterfactual mutation affects judgments of blame (Branscombe et al., 2003; Creyer \& Guerhan, 1997), regret (Sevdalis \& Kokkinaki, 2006), and emotion (Niedenthal et al., 1994). The present research extends these findings, showing that counterfactual thoughts also influence subsequent self-esteem and that stability of the mutated factor moderates these effects. Specifically, counterfactuals concerning unstable causes, such as a lack of effort, protected self-esteem following a negative performance (see also Covington \& Omelich, 1979; McCrea \& Hirt, 2001; Rhodewalt et al., 1991; Weiner, 1985). It is important to note that, although these effects are consistent with models of attribution, the consequences of counterfactuals for state self-esteem appeared to be independent of causal attributions, supporting past work showing that they are related yet independent processes (Mandel, 2003; Mandel \& Lehman, 1996).

The present studies also extend past work showing that although upward thoughts often result in more negative affect, these effects can also be reversed. For example, when individuals "reflect" on counterfactual alternatives, vividly imagining how the outcome could have been different, they are more likely to experience positive affect as a result of upward counterfactual thinking (Markman \& McMullen, 2003; Markman et al., 2008; McMullen, 1997). Similarly, the possibility to change an outcome in the future or a focus on process accountability results in affective assimilation (Boninger et al., 1994; Markman \& Tetlock, 2000a; McMullen \& Markman, 2002). Likewise, upward counterfactuals that can excuse a poor performance (i.e., by identifying an unstable factor as having prevented a better outcome) seem to lead to more positive self-esteem.

The ability of upward counterfactuals to excuse failure by shifting blame to unstable factors adds to a growing literature demonstrating the role of self-protection concerns in counterfactual thinking. For example, individuals have been shown to use counterfactual thoughts to deny responsibility for negative outcomes (Markman \& Tetlock, 2000b), make negative outcomes seem better by comparison (Markman et al., 1993), lower future expectations (Sanna et al., 2001), and suggest that external rather than internal factors prevented a better outcome for self and important ingroups (Goerke et al., 2004; McCrea, 2007; Roese \& Olson, 1993).

In addition to stressing the importance of the content of the counterfactual thought in determining affect and motivation, the present research also suggests that the same thought can have differing effects depending on the situational context. For example, the presence of a self-handicap in Study 2 altered the affective and motivational consequences of upward counterfactuals concerning preparative effort by allowing them to serve as an excuse. Furthermore, the consequences of these thoughts are likely dependent upon the goals of the individual to either protect the self or to improve. In many past studies, it appears that self-improvement motivations took precedence. As a result, individuals were more willing to accept increased negative affect in return for performance gains (Markman \& McMullen, 2003; Myers \& McCrea, 2008; Roese, 1994). In contrast, in the present studies, participants were motivated to excuse failure, and thus subsequent preparation and performance were reduced.

What then determines whether a particular counterfactual thought serves to excuse poor performance or to identify ways to improve and increase goal striving? A consideration of variables that motivate self-handicapping behavior may provide a starting point for answering this important remaining question. Although not an exhaustive list, tasks that are important and that have implications for self-evaluations of ability and intelligence (Shepperd \& Arkin, 1989a, 1989b), the experience of noncontingent success (Berglas \& Jones, 1978; Thompson, 2004), the presence of an audience (Hirt et al., 2000; Kolditz \& Arkin, 1982), the adoption of performance rather than mastery goals (Elliot, Cury, Fryer, \& Huguet, 2006; Urdan, 2004), and the framing of a task in prevention rather than promotion terms (Hendrix \& Hirt, 2008) have all been shown to increase self-handicapping behavior. Thus, 
these conditions would also likely motivate individuals to use counterfactuals for self-protection rather than for selfimprovement. In addition, the consequences of counterfactual thinking may be moderated by variables relating to the arousal of self-enhancement versus self-assessment motives (Sedikides \& Strube, 1997; Trope, 1986). For example, trait uncertainty (Sorrentino \& Hewitt, 1984; Trope, 1986), high trait malleability (Dunning, 1995; Dweck \& Leggett, 1988), and the prior satisfaction of self-protection and emotion-regulation concerns (D. K. Sherman \& Cohen, 2006; Trope, Ferguson, \& Raghunathan, 2001) may all increase the desire to use counterfactuals to accurately assess performance and spark self-improvement. These are fascinating questions for future research.

\section{Implications for the Effectiveness of Self-Handicapping}

In both Studies 1 and 2, the presence of a handicap in the form of reduced preparative effort increased the generation of upward counterfactual thoughts. These findings support the theorizing of S. J. Sherman and McConnell (1995) that self-handicapping appears to be intended to increase the availability of upward counterfactual thoughts that identify the handicap as having prevented a better performance. This effect also supports norm theory, in that the presence of a clear obstacle to success is likely to be seen as "abnormal" (Kahneman \& Miller, 1986) and thus more mutable. The finding that the increased availability of upward counterfactual thoughts can protect self-esteem following failure generates a number of interesting predictions concerning the effectiveness of different types of self-handicaps. Previous research has shown that counterfactuals, particularly when upward, are more likely to focus on controllable actions (Girotto, Legrenzi, \& Rizzo, 1991; Markman et al., 1995; Roese \& Olson, 1995c). Furthermore, selfhandicapping is related to prevention-based regulatory focus (Hendrix \& Hirt, 2008), and a prevention focus in turn is linked to an increase in the mutability of actions relative to inactions (Roese, Hur, \& Pennington, 1999). These findings suggest that selfhandicaps that involve a more active and controllable behavior (e.g., taking drugs or alcohol) may be more likely to elicit excusing counterfactuals than do uncontrollable or inactive handicaps (e.g., claiming lack of sleep). Indeed, the use of the induced compliance procedure in the present studies was designed to allow participants to generate upward counterfactual thoughts about a controllable self-handicap. On the other hand, such controllable, intentional handicaps are more likely to increase suspicion in others, rendering them less effective as impression-management strategies (Baumgardner \& Levy, 1988; Hirt, McCrea, \& Boris, 2003). It is not clear whether self-handicaps that are intentional are also less effective in self-protection. Self-handicaps may require a degree of selfdeception in order to protect self-esteem, such that individuals must convince themselves that the handicap was not intentional (Higgins \& Berglas, 1990). If so, then controllable handicaps might actually be less effective in protecting self-esteem. These issues await further research.

\section{Consequences of Self-Handicapping and Counterfactual Thinking for Performance}

One of the most intriguing aspects of the current research is the finding that excusing a poor performance undermines subsequent motivation to improve in the future as well as actual future performance. The preparative benefits of counterfactual thinking have been linked to the identification of useful strategies (Epstude \& Roese, 2008; Markman \& McMullen, 2003; Roese, 1994; Roese \& Olson, 1995b), increased self-efficacy and feelings of preparedness (Epstude \& Roese, 2008; Markman et al., 1995; Tal-Or et al., 2004), and increased motivation driven by negative affect (Epstude \& Roese, 2008; Markman \& McMullen, 2003; Markman et al., 2008; Myers \& McCrea, 2008). According to the reflection evaluation model (Markman \& McMullen, 2003; Markman et al., 2008), negative affect generated by upward counterfactual thinking is used as input into decisions of whether a goal has been reached. As a result, motivational and preparative benefits of upward counterfactuals are only observed when individuals process the thoughts in an evaluative mode and, as a result, experience increased negative affect (Markman et al., 2008). Consistent with this view, the present studies demonstrated that upward counterfactuals improve preparative behavior and performance only when they are not used to excuse a poor performance.

One slight difference between past studies (e.g., Markman et al., 2008; Myers \& McCrea, 2008) and those presented here is the role played by mood in the former and state self-esteem in the latter in determining subsequent motivation. Although further research is required to clarify these findings, one can tentatively suggest that the importance of the task for self-definition is critical here. The tasks in the present studies were designed to be ego threatening, whereas the tasks in earlier research (Markman et al., 2008; Myers $\&$ McCrea, 2008) were not. Thus, individuals may have viewed satisfaction with the self (rather than mood) as a more valid cue for motivation in the present studies.

Epstude and Roese (2008) classify the mechanisms by which counterfactuals can influence behavior as reflecting a contentspecific pathway (i.e., increasing the specific behavior mentioned in the thought) or a content-neutral pathway (e.g., increasing motivation or self-efficacy). The results of the present studies seem to be most consistent with a content-neutral, motivational process. In contrast to a strict content-specific benefit, participants at times behaved in a manner completely at odds with the strategy mentioned in the thoughts. For example, participants in Study 4 were least likely to choose to listen to helpful noise for the subsequent test when they considered how the distracting noise had impaired their performance. It is also not the case that these effects can be easily explained by underlying changes in self-efficacy. Preparative effects and performance benefits were found in those conditions in which self-esteem was low. Future researchers should address the question of when counterfactuals influence performance via a content-specific pathway and when they influence performance via a content-neutral pathway, as well as to what extent these different mechanisms can work in tandem (Epstude \& Roese, 2008). I am currently pursuing these issues in my laboratory.

Finally, in addition to clarifying the process by which counterfactuals influence subsequent motivation and performance, the present results suggest that self-handicapping can impair long-term achievement by undermining subsequent motivation to improve. Such a mechanism has not been previously demonstrated in the self-handicapping literature. Empirical studies of the performance consequences of self-handicapping have yielded mixed results Although self-handicapping likely reduces evaluation apprehen- 
sion and thus may benefit performance at times (Leary, 1986), handicaps involving a lack of preparation or impairment likely directly undermine performance (Elliot et al., 2006; McCrea \& Hirt, 2001). Indeed, long-term academic performance seems to be negatively related to the tendency to self-handicap, in particular to reduced study effort (McCrea \& Hirt, 2001; McCrea et al., in press; Urdan, 2004; Zuckerman et al., 1998). It has generally been assumed that such reduced study effort reflects ongoing selfhandicapping behavior (McCrea \& Hirt, 2001; Zuckerman et al., 1998). However, the current studies suggest that merely blaming one's failure on a handicap can reduce subsequent motivation to prepare, resulting in worse performance. Thus, poor study effort and declining academic performance may reflect reduced motivation resulting from self-esteem protection. To the extent that individuals are unwilling to accept responsibility for their poor performance, they are unlikely to engage in self-improvement or apply any "lessons learned" to a subsequent task. Indeed, a wider literature suggests that excuse-making and self-protection can undermine attempts to gain control over challenging situations and pursue important goals (Baumeister \& Tice, 1985; Crocker, Brook, Niiya, \& Villacorta, 2006; Rothbaum, Weisz, \& Snyder, 1982). Researchers interested in the effects of self-handicapping on performance should therefore examine reduced motivation and task disengagement as possible causes of long-term performance impairment.

\section{Conclusion}

Past research on counterfactual thinking has emphasized the various functions for the individual that these thoughts can serve. Counterfactual thoughts have been argued to serve either a preparative function or an affective function. The present research demonstrates that upward counterfactual thoughts can excuse poor performances, consistent with an affective function, but at a cost to any preparative function. Particularly in the case of selfhandicapping, upward counterfactuals may allow individuals to continue to believe that they could have succeeded, yet make actual achievement less likely. In other words, upward counterfactuals offer self-handicappers the opportunity to be "legends in their own minds," maintaining the belief that they have ability despite objective evidence to the contrary.

\section{References}

Aiken, L. S., \& West, S. G. (1991). Multiple regression: Testing and interpreting interactions. Thousand Oaks, CA: Sage.

Algom, D., Raphaeli, N., \& Cohen-Raz, L. (1986). Integration of noxious stimulation across separate somatosensory communication systems: A functional theory of pain. Journal of Experimental Psychology: Human Perception and Performance, 12, 92-102.

Amthauer, R., Brocke, B., Liepmann, D., \& Beauducel, A. (2001). Intelligenz-Struktur-Test $2000 R$ (2nd ed.). Goettingen, Germany: Hogrefe Verlag.

Bargh, J. A., Gollwitzer, P. M., Lee-Chai, A., Barndollar, K., \& Troetschel, R. (2001). The automated will: Nonconscious activation and pursuit of behavioral goals. Journal of Personality and Social Psychology, 81, 1014-1027.

Baumeister, R. F., \& Tice, D. M. (1985). Self-esteem and responses to success and failure: Subsequent performance and intrinsic motivation. Journal of Personality, 53, 450-467.

Baumgardner, A. H., \& Levy, P. E. (1988). Role of self-esteem in percep- tions of ability and effort: Illogic or insight? Personality and Social Psychology Bulletin, 14, 429-438.

Berglas, S., \& Jones, E. E. (1978). Drug choice as a self-handicapping strategy in response to noncontingent success. Journal of Personality and Social Psychology, 36, 405-417.

Boninger, D. S., Gleicher, F., \& Strathman, A. (1994). Counterfactual thinking: From what might have been to what may be. Journal of Personality and Social Psychology, 67, 297-307.

Branscombe, N. R., Wohl, M. J. A., Owen, S., Allison, J. A., \& N'Gbala, A. (2003). Counterfactual thinking, blame assignment, and well-being in rape victims. Basic and Applied Social Psychology, 25, 265-273.

Brown, R. P., \& Josephs, R. A. (1999). A burden of proof: Stereotype relevance and gender differences in math performance. Journal of Personality and Social Psychology, 76, 246-257.

Cattell, R. B., \& Cattell, A. K. S. (1961). Test of " $g$ ": Culture fair intelligence test. Champaign, IL: The Institute for Personality and Ability Testing.

Covington, M. V., \& Omelich, C. L. (1979). Effort: The double-edged sword in school achievement. Journal of Educational Psychology, 71, $169-182$.

Creyer, E. H., \& Guerhan, Z. (1997). Who's to blame? Counterfactual reasoning and the assignment of blame. Psychology and Marketing, 14, 209-222.

Crocker, J., Brook, A. T., Niiya, Y., \& Villacorta, M. (2006). The pursuit of self-esteem: Contingencies of self-worth and self-regulation. Journal of Personality, 74, 1749-1771.

Dunning, D. (1995). Trait importance and modifiability as factors influencing self-assessment and self-enhancement motives. Personality and Social Psychology Bulletin, 21, 1297-1306.

Dweck, C. S., \& Leggett, E. L. (1988). A social cognitive approach to motivation and personality. Psychological Review, 95, 256-273.

Elliot, A. J., Cury, F., Fryer, J. W., \& Huguet, P. (2006). Achievement goals, self-handicapping, and performance attainment: A mediational analysis. Journal of Sport and Exercise Psychology, 28, 344-361.

Epstude, K., \& Roese, N. J. (2008). The functional theory of counterfactual thinking. Personality and Social Psychology Review, 12, 168-192.

Feick, D. L., \& Rhodewalt, F. (1997). The double-edged sword of selfhandicapping: Discounting, augmentation, and the protection and enhancement of self-esteem. Motivation and Emotion, 21, 147-163.

Festinger, L., \& Carlsmith, J. M. (1959). Cognitive consequences of forced compliance. Journal of Abnormal and Social Psychology, 58, 203-210.

Girotto, V., Legrenzi, P., \& Rizzo, A. (1991). Event controllability in counterfactual thinking. Acta Psychologica, 78, 111-133.

Goerke, M., Möller, J., Schulz-Hardt, S., Napiersky, U., \& Frey, D. (2004). "It's not my fault-but only I can change it": Counterfactual and prefactual thoughts of managers. Journal of Applied Psychology, 89, 279-292.

Harris, R. N., \& Snyder, C. R. (1986). The role of uncertain self-esteem in self-handicapping. Journal of Personality and Social Psychology, 51, 451-458.

Hendrix, K. S., \& Hirt, E. R. (2008). Stressed out over possible failure: The effects of induced self-regulatory focus on claimed self-handicapping. Unpublished manuscript, Indiana University Bloomington.

Higgins, R. L., \& Berglas, S. (1990). The maintenance and treatment of self-handicapping: From risk-taking to face-saving-and back. In R. L. Higgins (Ed.), Self-handicapping: The paradox that isn't. The Plenum series in social/clinical psychology (pp. 187-238). New York: Plenum.

Higgins, R. L., \& Harris, R. N. (1988). Strategic "alcohol" use: Drinking to self-handicap. Journal of Social and Clinical Psychology, 6, 191-202.

Hirt, E. R., Deppe, R. K., \& Gordon, L. J. (1991). Self-reported versus behavioral self-handicapping: Empirical evidence for a theoretical distinction. Journal of Personality and Social Psychology, 61, 981-991.

Hirt, E. R., McCrea, S. M., \& Boris, H. I. (2003). "I know you selfhandicapped last exam": Gender differences in reactions to self- 
handicapping. Journal of Personality and Social Psychology, 84, 177193.

Hirt, E. R., McCrea, S. M., \& Kimble, C. E. (2000). Public self-focus and sex differences in behavioral self-handicapping: Does increasing selfthreat still make it "just a man's game"? Personality and Social Psychology Bulletin, 26, 1131-1141.

Jones, E. E., \& Berglas, S. (1978). Control of attributions about the self through self-handicapping strategies: The appeal of alcohol and the role of underachievement. Personality and Social Psychology Bulletin, 4, 200-206.

Kahneman, D., \& Miller, D. T. (1986). Norm theory: Comparing reality to its alternatives. Psychological Review, 93, 136-153.

Kanner, A. D., Coyne, J. C., Schaeffer, C., \& Lazarus, R. S. (1981). Comparison of two modes of stress measurement: Daily hassles and uplifts versus major life events. Journal of Behavioral Medicine, 4, $1-39$.

Kolditz, T. A., \& Arkin, R. M. (1982). An impression management interpretation of the self-handicapping strategy. Journal of Personality and Social Psychology, 43, 492-502.

Leary, M. R. (1986). The impact of interactional impediments on social anxiety and self-presentation. Journal of Experimental Social Psychology, 22, 122-135.

Mandel, D. R. (2003). Judgment dissociation theory: An analysis of differences in causal, counterfactual, and covariational reasoning. Journal of Personality and Social Psychology, 132, 419-434.

Mandel, D. R., \& Lehman, D. R. (1996). Counterfactual thinking and ascriptions of cause and preventability. Journal of Personality and Social Psychology, 71, 450-463.

Markman, K. D., Gavanski, I., Sherman, S. J., \& McMullen, M. N. (1993). The mental simulation of better and worse possible worlds. Journal of Experimental Social Psychology, 29, 87-109.

Markman, K. D., Gavanski, I., Sherman, S. J., \& McMullen, M. N. (1995). The impact of perceived control on the imagination of better and worse possible worlds. Personality and Social Psychology Bulletin, 21, 588595.

Markman, K. D., \& McMullen, M. N. (2003). A reflection and evaluation model of comparative thinking. Personality and Social Psychology Review, 7, 244-267.

Markman, K. D., McMullen, M. N., \& Elizaga, R. A. (2008). Counterfactual thinking, persistence, and performance: A test of the Reflection and Evaluation Model. Journal of Experimental Social Psychology, 44, 421-428.

Markman, K. D., \& Tetlock, P. E. (2000a). Accountability and close-call counterfactuals: The loser who nearly won and the winner who nearly lost. Personality and Social Psychology Bulletin, 26, 1213-1224.

Markman, K. D., \& Tetlock, P. E. (2000b). 'I couldn't have known': Accountability, foreseeability and counterfactual denials of responsibility. British Journal of Social Psychology, 39, 313-325.

McCrea, S. M. (2007). Counterfactual thinking following negative outcomes: Evidence for group and self-protective biases. European Journal of Social Psychology, 37, 1256-1271.

McCrea, S. M., \& Hirt, E. R. (2001). The role of ability judgments in self-handicapping. Personality and Social Psychology Bulletin, 27, $1378-1389$.

McCrea, S. M., Hirt, E. R., Hendrix, K. S., Milner, B. J., \& Steele, N. L. (in press). The Worker scale: Developing a measure to explain gender differences in behavioral self-handicapping. Journal of Research in Personality.

McCrea, S. M., Hirt, E. R., \& Milner, B. J. (2008). She works hard for the money: Valuing effort underlies gender differences in behavioral selfhandicapping. Journal of Experimental Social Psychology, 44, 292-311.

McFarland, C., \& Ross, M. (1982). Impact of causal attributions on affective reactions to success and failure. Journal of Personality and Social Psychology, 43, 937-946.
McMullen, M. N. (1997). Affective contrast and assimilation in counterfactual thinking. Journal of Experimental Social Psychology, 33, 77100 .

McMullen, M. N., \& Markman, K. D. (2000). Downward counterfactuals and motivation: The wake-up call and the Pangloss effect. Personality and Social Psychology Bulletin, 26, 575-584.

McMullen, M. N., \& Markman, K. D. (2002). Affective impact of close counterfactuals: Implications of possible futures for possible pasts. Journal of Experimental Social Psychology, 38, 64-70.

Myers, A. L., \& McCrea, S. M. (2008). The preparative function of counterfactual thinking: Providing useful strategies or enhancing motivation. Unpublished manuscript, University of Konstanz, Germany.

Niedenthal, P. M., Tangney, J. P., \& Gavanski, I. (1994). "If only I weren't" versus "If only I hadn't": Distinguishing shame and guilt in counterfactual thinking. Journal of Personality and Social Psychology, $67,585-595$

Oleson, K. C., Poehlmann, K. M., Yost, J. H., Lynch, M. E., \& Arkin, R. M. (2000). Subjective overachievement: Individual differences in self-doubt and concern with performance. Journal of Personality, 68, 491-524.

Ouis, D. (2001). Annoyance from road traffic noise: A review. Journal of Environmental Psychology, 21, 101-120.

Rhodewalt, F. (1990). Self-handicappers: Individual differences in the preference for anticipatory, self-protective acts. In R. L. Higgins, C. R. Snyder, \& S. Berglas (Eds.), Self-handicapping: The paradox that isn't. The Plenum series in social/clinical psychology (pp. 69-106). New York: Plenum.

Rhodewalt, F., Morf, C., Hazlett, S., \& Fairfield, M. (1991). Selfhandicapping: The role of discounting and augmentation in the preservation of self-esteem. Journal of Personality and Social Psychology, 61, $122-131$.

Roese, N. J. (1994). The functional basis of counterfactual thinking. Journal of Personality and Social Psychology, 66, 805-818.

Roese, N. J., Hur, T., \& Pennington, G. L. (1999). Counterfactual thinking and regulatory focus: Implications for action versus inaction and sufficiency versus necessity. Journal of Personality and Social Psychology, 77, 1109-1120.

Roese, N. J., \& Olson, J. M. (1993). Self-esteem and counterfactual thinking. Journal of Personality and Social Psychology, 65, 199-206.

Roese, N. J., \& Olson, J. M. (1995a). Counterfactual thinking: A critical overview. In N. J. Roese \& J. M. Olson (Eds.), What might have been: The social psychology of counterfactual thinking (pp. 1-55). Hillsdale, NJ: Erlbaum.

Roese, N. J., \& Olson, J. M. (1995b). Functions of counterfactual thinking. In N. J. Roese \& J. M. Olson (Eds.), What might have been: The social psychology of counterfactual thinking (pp. 169-197). Hillsdale, NJ: Erlbaum.

Roese, N. J., \& Olson, J. M. (1995c). Outcome controllability and counterfactual thinking. Personality and Social Psychology Bulletin, 21, $620-628$

Rosenberg, M. (1965). Society and adolescent self-image. Princeton, NJ: Princeton University Press.

Rothbaum, F., Weisz, J. R., \& Snyder, S. S. (1982). Changing the world and changing the self: A two-process model of perceived control. Journal of Personality and Social Psychology, 42, 5-37.

Sanna, L. J., Carter, S. E., \& Small, E. M. (2006). The road not taken: Counterfactual thinking over time. In L. J. Sanna \& E. C. Chang (Eds.), Judgments over time: The interplay of thoughts, feelings, and behaviors (pp. 163-181). New York: Oxford University Press.

Sanna, L. J., Chang, E. C., \& Meier, S. (2001). Counterfactual thinking and self-motives. Personality and Social Psychology Bulletin, 27, 1023 1034.

Sedikides, C., \& Strube, M. J. (1997). Self-evaluation: To thine own self be good, to thine own self be sure, to thine own self be true, and to thy own 
self be better. In M. P. Zanna (Ed.), Advances in experimental social psychology (Vol. 29, pp. 209-269). New York: Academic Press.

Sevdalis, N., \& Kokkinaki, F. (2006). The differential effect of realistic and unrealistic counterfactual thinking on regret. Acta Psychologica, 122, 111-128.

Shepperd, J. A., \& Arkin, R. M. (1989a). Determinants of selfhandicapping: Task importance and the effects of preexisting handicaps on self-generated handicaps. Personality and Social Psychology Bulletin, 15, 101-112.

Shepperd, J. A., \& Arkin, R. M. (1989b). Self-handicapping: The moderating roles of public self-consciousness and task importance. Personality and Social Psychology Bulletin, 15, 252-265.

Sherman, D. K., \& Cohen, G. L. (2006). The psychology of self-defense: Self-affirmation theory. In M. P. Zanna (Ed.), Advances in experimental social psychology (Vol. 38, pp. 183-242). San Diego, CA: Elsevier.

Sherman, S. J., \& McConnell, A. R. (1995). Dysfunctional implications of counterfactual thinking: When alternatives to reality fail us. In N. J. Roese \& J. M. Olson (Eds.), What might have been: The social psychology of counterfactual thinking (pp. 199-231). Hillsdale, NJ: Erlbaum.

Smith, E. E. (1961). The power of dissonance techniques to change attitudes. Public Opinion Quarterly, 25, 626-639.

Sorrentino, R. M., \& Hewitt, E. C. (1984). The uncertainty-reducing properties of achievement tasks revisited. Journal of Personality and Social Psychology, 47, 884-899.

Tabachnik, B. G., \& Fidell, L. S. (2001). Using multivariate statistics (4th ed.). New York: HarperCollins.
Tal-Or, N., Boninger, D. S., \& Gleicher, F. (2004). On becoming what we might have been: Counterfactual thinking and self-efficacy. Self and Identity, 3, 5-26.

Thompson, T. (2004). Re-examining the effects of noncontingent success on self-handicapping behaviour. British Journal of Educational Psychology, 74, 239-260.

Trope, Y. (1986). Self-enhancement and self-assessment in achievement behavior. In R. M. Sorrentino \& E. T. Higgins (Eds.), Handbook of motivation and cognition: Foundations of social behavior (pp. 350378). New York: Guilford Press.

Trope, Y., Ferguson, M., \& Raghunathan, R. (2001). Mood as a resource in processing self-relevant information. Mahwah, NJ: Erlbaum.

Urdan, T. (2004). Predictors of academic self-handicapping and achievement: Examining achievement goals, classroom goal structures, and culture. Journal of Educational Psychology, 96, 251-264.

Weiner, B. (1985). An attributional theory of achievement motivation and emotion. Psychological Review, 92, 548-573.

Wells, G. L., \& Gavanski, I. (1989). Mental simulation of causality. Journal of Personality and Social Psychology, 56, 161-169.

Zuckerman, M., Kieffer, S. C., \& Knee, C. R. (1998). Consequences of self-handicapping: Effects on coping, academic performance, and adjustment. Journal of Personality and Social Psychology, 74, 1619-1628. 